\title{
Modular nanotransporters: a multipurpose in vivo working platform for targeted drug delivery
}

This article was published in the following Dove Press journal:

International Journal of Nanomedicine

30 January 2012

Number of times this article has been viewed

\author{
Tatiana A Slastnikova ${ }^{1,2}$ \\ Andrey A Rosenkranz ${ }^{1,2}$ \\ Pavel V Gulak' \\ Raymond M Schiffelers ${ }^{3}$ \\ Tatiana N Lupanova ${ }^{1,4}$ \\ Yuri V Khramtsov' \\ Michael R Zalutsky ${ }^{5}$ \\ Alexander S Sobolev 1,2 \\ 'Laboratory of Molecular Genetics \\ of Intracellular Transport, Institute \\ of Gene Biology, Moscow, Russia; \\ ${ }^{2}$ Department of Biophysics, Biological \\ Faculty, Moscow State University, \\ Vorobyevy Gory, Moscow, Russia; \\ ${ }^{3}$ Laboratory for Clinical Chemistry \\ and Haematology, University \\ Medical Center Utrecht, Utrecht, \\ the Netherlands; ${ }^{4}$ Department of \\ Bioengineering, Biological Faculty, \\ Moscow State University, Vorobyevy \\ Gory, Moscow, Russia; ${ }^{5}$ Department \\ of Radiology, Duke University Medical \\ Center, Durham, NC, USA
}

Correspondence: Alexander Sobolev Institute of Gene Biology, Russian Academy of Sciences, 34/5 Vavilov St, Moscow I 19334, Russia

$\mathrm{Tel}+7499$ I35 3100

Fax +7499 I35 4I05

Email sobolev@igb.ac.ru
Background: Modular nanotransporters (MNT) are recombinant multifunctional polypeptides created to exploit a cascade of cellular processes, initiated with membrane receptor recognition to deliver selective short-range and highly cytotoxic therapeutics to the cell nucleus. This research was designed for in vivo concept testing for this drug delivery platform using two modular nanotransporters, one targeted to the $\alpha$-melanocyte-stimulating hormone ( $\alpha \mathrm{MSH})$ receptor overexpressed on melanoma cells and the other to the epidermal growth factor (EGF) receptor overexpressed on several cancers, including glioblastoma, and head-and-neck and breast carcinoma cells.

Methods: In vivo targeting of the modular nanotransporter was determined by immunofluorescence confocal laser scanning microscopy and by accumulation of ${ }^{125}$ I-labeled modular nanotransporters. The in vivo therapeutic effects of the modular nanotransporters were assessed by photodynamic therapy studies, given that the cytotoxicity of photosensitizers is critically dependent on their delivery to the cell nucleus.

Results: Immunohistochemical analyses of tumor and neighboring normal tissues of mice injected with multifunctional nanotransporters demonstrated preferential uptake in tumor tissue, particularly in cell nuclei. With ${ }^{125}$ I-labeled MNT $\{\alpha \mathrm{MSH}\}$, optimal tumor:muscle and tumor:skin ratios of 8:1 and 9.8:1, respectively, were observed 3 hours after injection in B16F1 melanoma-bearing mice. Treatment with bacteriochlorin $p-\mathrm{MNT}\{\alpha \mathrm{MSH}\}$ yielded $89 \%-98 \%$ tumor growth inhibition and a two-fold increase in survival for mice with B16-F1 and Cloudman S91 melanomas. Likewise, treatment of A431 human epidermoid carcinoma-bearing mice with chlorin $\mathrm{e}_{6}-\mathrm{MNT}\{\mathrm{EGF}\}$ resulted in 94\% tumor growth inhibition compared with free chlorin $\mathrm{e}_{6}$, with $75 \%$ of animals surviving at 3 months compared with $0 \%$ and $20 \%$ for untreated and free chlorin $\mathrm{e}_{6}$-treated groups, respectively.

Conclusion: The multifunctional nanotransporter approach provides a new in vivo functional platform for drug development that could, in principle, be applicable to any combination of cell surface receptor and agent (photosensitizers, oligonucleotides, radionuclides) requiring nuclear delivery to achieve maximum effectiveness.

Keywords: drug delivery, nanobiotechnology, nanomedicine, cancer therapy, photosensitizers, multifunctional nanotransporter

\section{Introduction}

The development of therapeutic options for cancer that are both selective and effective presents a major challenge in contemporary biomedicine. Specific delivery and binding to malignant cell populations can be achieved by targeting cell surface receptors that are either uniquely expressed or overexpressed on cancer cells. A variety of receptor-avid ligands have been evaluated for this purpose, either 
alone or affixed to nanoparticles, ${ }^{1,2}$ including antibodies ${ }^{3}$ and their fragments, ${ }^{4}$ other proteins,${ }^{5}$ peptides,${ }^{6}$ and aptamers. ${ }^{7}$ After binding to the targeted receptor, the fate of the ligand-drug bioconjugate can be either to remain on the cell membrane or to be transported into the cytoplasm. ${ }^{8}$ However, the efficiency of most therapeutics depends to a large extent on their subcellular localization, and for many of them, the most vulnerable compartment is the nucleus. Furthermore, certain types of therapeutics, such as photosensitizers ${ }^{9}$ and Auger electron emitting radionuclides, ${ }^{10}$ have ranges of action of less than $0.1 \mu \mathrm{m}$, which is a major advantage for minimizing damage to normal tissues adjacent to tumor tissue, but renders their cytotoxic effectiveness almost exclusively dependent on achieving delivery to the cell nucleus. ${ }^{11}$

Vehicles that efficiently deliver therapeutic agents to their locus in quo in tumor tissue engage receptors on the cancer cell surface. Transporting their payload to the cell nucleus would be attractive from the standpoint of maximizing both the specificity and effectiveness of tumor treatment. Our efforts to achieve these goals have been focused on nanobiotechnological creation of an artificial multifunctional transporting platform, ie, the recombinant modular nanotransporter (MNT). ${ }^{12}$ The MNT is a modular polypeptide that can contain four moieties, ie, an internalizable ligand to provide target cell recognition and receptormediated endocytosis by the cell, an endosomolytic module to facilitate escape from endosomes, a nuclear localization sequence (NLS) motif to allow active transport into the cell nucleus via binding to cytoplasmic importins, and a carrier domain for efficient attachment of the drug (Figure 1).
In fact, MNT is an artificially generated detail of the cell transport machinery (or a nanodevice, which exploits the cell transport machinery) that was designed for cell-specific transport into a preassigned cellular compartment (the cell nucleus in this case).

Pursuing this strategy, ${ }^{13}$ we designed, produced, and characterized bacterially-expressed MNT comprising $\alpha$-melanocyte-stimulating hormone ( $\alpha \mathrm{MSH})$ or epidermal growth factor (EGF) for targeting $\alpha \mathrm{MSH}$ receptors that are overexpressed in melanoma ${ }^{14}$ or the epidermal growth factor receptor (EGFR) that is overexpressed on several cancers, including head and neck, breast carcinoma, and glioblastoma, ${ }^{15}$ the optimized nuclear localization sequence from SV40 large tumor antigen, the Escherichia coli hemoglobinlike protein (HMP) as a carrier module, and a translocation domain of diphtheria toxin as the endosomolytic amphipathic module (DTox). Having demonstrated that MNT could be produced and purified efficiently, with retention of function of each of the modules, and having shown that every module is necessary for the maximum MNT activity, ${ }^{12,16}$ we next evaluated their potential utility as a platform for targeted cancer therapy. Conjugation of the photosensitizer chlorin $\mathrm{e}_{6}$ to the MNT DTox-HMP-NLS-EGF increased cytotoxicity by a factor of more than 3000 for the EGFR-expressing A431 human epidermoid carcinoma cell line compared with free chlorin $\mathrm{e}_{6}{ }^{16}$

Herein, we investigate the in vivo characteristics of these MNT, designed to deliver photosensitizers to $\alpha \mathrm{MSH}$ receptor-expressing and EGFR-expressing tumors. Evidence is provided that MNT selectively accumulates in cancer cells, with the highest concentration in the cell nuclei.

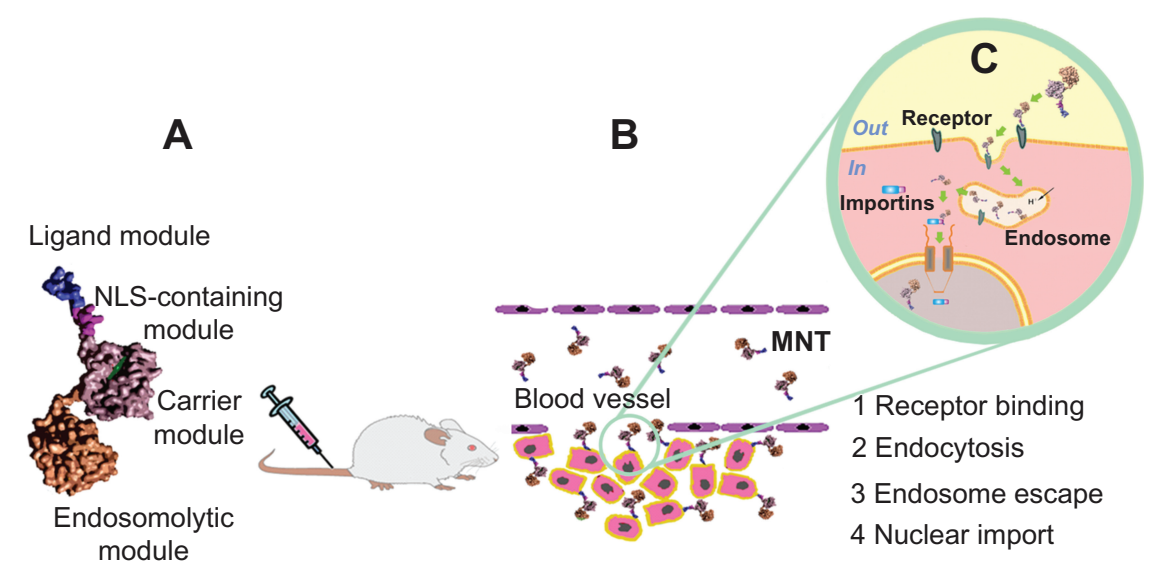

Figure I Schematic for construction and delivery of a modular nanotransporter to the nucleus of tumor cells. (A) Modular nanotransporter consisting of four functional modules. (B) After intravenous administration, the modular nanotransporter binds via its ligand module to receptors expressed on the surface of tumor cells. (C) The modular nanotransporter is delivered to endosomes via receptor-mediated endocytosis, undergoes endosome escape through its endosomolytic module, binds via its nuclear localization sequence module to importins in the cytoplasm, and is transported through the nuclear pore to the cell nucleus.

Abbreviations: MNT, modular nanotransporter; NLS, nuclear localization sequence. 
Importantly, MNT-mediated delivery of photosensitizers resulted in more than $90 \%$ tumor growth inhibition and significantly prolonged survival compared with the free drug, while producing few if any side effects.

\section{Materials and methods Synthesis of MNT}

DTox-HMP-NLS- $\alpha$ MSH (70.4 kDa) and DTox-HMPNLS-EGF (76.3 kDa) were synthesized and purified as described elsewhere. ${ }^{12,16}$ Briefly, MNT were expressed in an E. coli strain M15 carrying plasmid pREP4 according to the QIAGEN protocol. The cells were lysed and the MNT were purified on Ni-NTA agarose (QIAGEN) according to the standard procedure. The MNT were then dialyzed against $10 \mathrm{mM}$ sodium phosphate buffer $(\mathrm{pH} 8)$ containing $150 \mathrm{mM} \mathrm{NaCl}$.

\section{Determination of mean hydrodynamic diameter of MNT}

Particle sizes of DTox-HMP-NLS-EGF $(66 \mu \mathrm{M})$ in $10 \mathrm{mM}$ sodium phosphate buffer ( $\mathrm{pH} 8$ ) containing $150 \mathrm{mM} \mathrm{NaCl}$ were measured using a ZetaPALS (Brookhaven Instruments, Holtsville NY). The instrument was validated with nanosphere size standards (polystyrene microspheres in water, $92 \pm 3.7 \mathrm{~nm}$ ) from Duke Scientific (Palo Alto, CA). The scattered light was detected at a $90^{\circ}$ angle. Measurements were performed in $40 \mu \mathrm{L}$ quartz cuvettes at $25^{\circ} \mathrm{C}$ with count rates of about $80 \mathrm{kCps}$ in ten runs of 240 seconds in duration each and analyzed by multimodal size distribution analysis.

\section{Determination of MNT size in supported lipid bilayers}

A Digital Instruments multimode scanning probe microscope on a Nanoscope IIIa (Veeco Instruments, Woodbury, NY) controller fitted with a J-scanner (165 $\mu \mathrm{m}$ maximum scan size) and a tapping mode liquid cell were used to image MNT molecules in the lipid bilayer in situ. A piece of mica was attached to a $1.6 \mathrm{~cm}$ diameter metal disk supplied by Veeco and installed in the microscope. The tapping mode liquid cell was fitted with inlet and outlet tubing to allow exchange of solutions in the cell during imaging. Samples of supported unilamellar bilayers were prepared as described earlier. ${ }^{16,17}$ Oxide-sharpened silicon nitride $\mathrm{V}$-shaped cantilevers with a nominal force constant of $0.06 \mathrm{~N} / \mathrm{m}$ and a tip with a $10 \mathrm{~nm}$ curvature radius were used and the forces were minimized during the scans. The silicon nitride cantilevers were irradiated with ultraviolet light prior to imaging to remove any adventitious organic contaminants. All measurements were performed in contact and tapping modes (cantilever drive frequencies approximately $9 \mathrm{kHz}$ ) at room temperature using a tip scan rate of about $2-4 \mathrm{~Hz}$. All images were captured as $512 \times 512$ pixels and were flattened and smoothed.

MNT (DTox-HMP-NLS-EGF) caused formation of two types of defects in previously intact parts of the bilayer, ie, fluctuating holes, partially edged with "heights" and circular structures with "ramparts" in the lipid bilayers (Figure 2B). ${ }^{16,17}$ The mean width of these circular structures and their mean diameter were measured (Figure 2B). The width was measured in the plane of the lipid bilayer. The mean width of the MNT
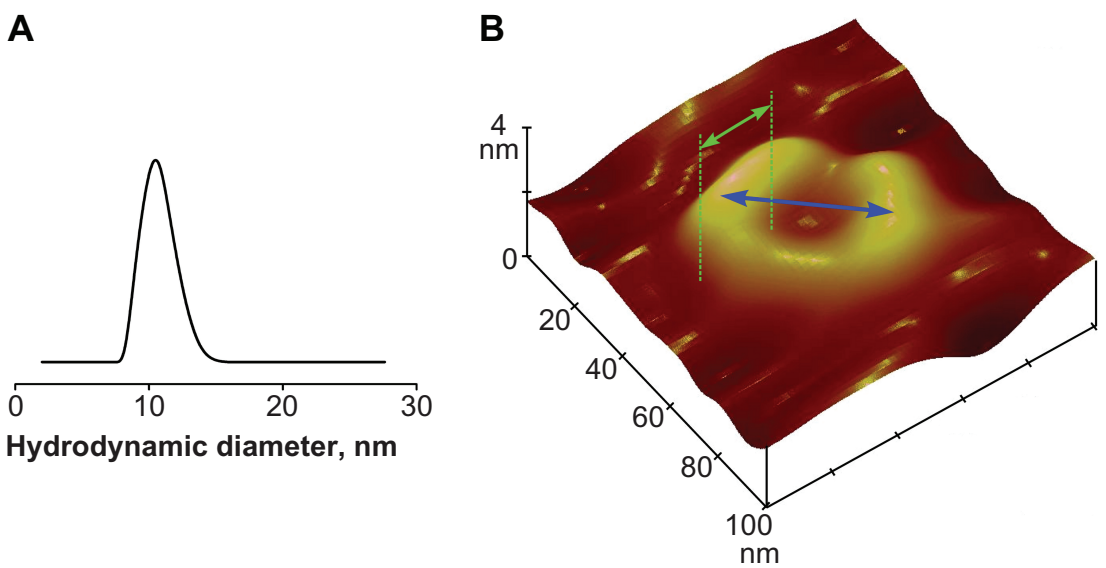

Figure 2 Dimensions of the modular nanotransporter and resulting circular structures. (A) Particle size distribution for a DTox-HMP-NLS-EGF sample (66 $\mu$ M) in I0 mM sodium phosphate buffer $(\mathrm{pH} 8)$ containing $150 \mathrm{mM} \mathrm{NaCl}$ as measured by dynamic light scattering; the mean hydrodynamic diameter of the modular nanotransporter was $10.6 \pm 0.5 \mathrm{~nm}$. (B) Atomic force microscopy tapping mode height image (100 $100 \mathrm{~nm}$; z-scale, $4 \mathrm{~nm})$ of egg yolk phosphatidylcholine bilayer recorded in $20 \mathrm{mM}$ HEPES-MES buffer with $150 \mathrm{mM} \mathrm{NaCl}(\mathrm{pH} 5.5)$ containing $5 \mathrm{nM}$ DTox-HMP-NLS-EGF. Mean diameter of circular structures was $43 . \mathrm{I} \pm 1.2 \mathrm{~nm}( \pm S E M)$ and mean width of these structures was $20.8 \pm 0.8 \mathrm{~nm}( \pm$ SEM). After correction for a widening of this width caused by final sizes of tips, the mean width of the MNT was I2.5 \pm I.9 $\mathrm{nm}( \pm$ SEM).

Note: Blue and green double arrows represent the diameter and width of the circular structure, respectively.

Abbreviations: MNT, modular nanotransporter; DTox, translocation domain of diphtheria toxin; HMP, Escherichia coli hemoglobin-like protein; NLS, nuclear localization sequence; EGF, epidermal growth factor; SEM, standard error of mean. 
molecule was calculated as the mean width of circular structures with correction for a widening caused by final sizes of the tips. This correction was made under the condition $r_{1} \geq h_{c} / 2$ according to the following formula: $\Delta d=\sqrt{8 \cdot r_{1} \cdot h_{c}}-h_{c}$, where $\Delta d$, is the widening of apparent width of circular structures; $r_{1}$ is the tip curvature radius; and $h_{c}$ is the mean height of circular structures. The height of the MNT molecule was calculated as the height above the mica surface of the molecules observed on the border of fluctuating holes. The mean length of the MNT molecule in the lipid bilayer $(l)$ was calculated using its mean height $(h)$, mean width $(w)$ and volume $\left(V=\pi D^{3} / 6\right)$, where $D$ is the mean hydrodynamic diameter. The shape of the MNT molecule in lipid bilayer was approximated as an ellipsoid, where $l=6 \mathrm{~V} / \pi h w$.

\section{Labeling MNT}

DTox-HMP-NLS- $\alpha$ MSH was labeled with ${ }^{125} \mathrm{I}$ by reaction with $N$-succinimidyl 3-[ ${ }^{125}$ I] iodobenzoate ${ }^{18}$ in $50 \mathrm{mM}$ borate buffer and purified on a PD10 gel filtration column (Amersham Biosciences, Piscataway, NJ).

\section{Photosensitizers}

Chlorin $\mathrm{e}_{6}$ was obtained from Frontier Scientific (Logan, UT) and bacteriochlorin $p$ was kindly provided by the Moscow State Academy of Fine Chemical Technologies.

\section{Coupling photosensitizers to MNT}

Photosensitizers were coupled to MNT using 1-ethyl-3(3-dimethylaminopropyl)-carbodiimide and $N$-hydroxysuccinimide (Sigma, St Louis, MO). Conjugates were purified by gel filtration on a Sephadex-G50 (Pharmacia, Philadelphia, PA) column in the presence of $1.5 \mathrm{M}$ guanidine hydrochloride or by affinity chromatography on Ni-NTA agarose (QIAGEN).

\section{Cell culture}

A431 human epidermoid carcinoma cells overexpressing EGFR, as well as Cloudman S91 (clone M3) and B16F1 murine melanoma cells overexpressing $\alpha \mathrm{MSH}$ receptors were maintained in Dulbecco's Modified Eagle Medium supplemented with $10 \%$ fetal calf serum and $50 \mu \mathrm{g} / \mathrm{mL}$ gentamicin. All cell lines were maintained at $37^{\circ} \mathrm{C}$ in a $5 \% \mathrm{CO}_{2}$ humidified atmosphere. A431 and B16-F1 cells were obtained from the American Type Culture Collection and passed in the laboratory through less than 30 passages.

\section{Mice}

All animal procedures were conducted in accordance with procedures approved by the Dierexperimentencommissie
Faculteit Farmacie/Scheikunde/Biologie, the Gemeenschappelijk Dieren Laboratorium, and the Institute of Gene Biology.

\section{Delayed-type hypersensitivity reaction}

Subcutaneous injection of MNT was performed to evaluate delayed-type hypersensitivity reactions (see Supplementary data, Materials and methods section).

\section{MNT tissue distribution}

Female C57 black/6J mice were inoculated subcutaneously with $1 \times 10^{6}$ B16-F1 murine melanoma cells, and 7-13 days later ${ }^{125}$ I-labeled DTox-HMP-NLS- $\alpha$ MSH ([$\left.{ }^{125} \mathrm{I}\right]$ iodoMNT) was injected intravenously in $500 \mu \mathrm{L}$ of saline with gentamicin $50 \mu \mathrm{g} / \mathrm{mL}$ as follows: $850 \mu \mathrm{g}$, specific activity $6.5 \mu \mathrm{Ci} / \mathrm{mg}$, three mice; $214 \mu \mathrm{g}$, specific activity $36 \mu \mathrm{Ci} / \mathrm{mg}$, three mice; and $11 \mu \mathrm{g}$, specific activity $224 \mu \mathrm{Ci} / \mathrm{mg}$, nine mice. Biodistribution was studied for all doses at 3 hours, and the $11 \mu \mathrm{g}$ dose was also evaluated at 70 minutes and 15 hours. Mice were anesthetized, euthanized, and their tumors and proximal skin and muscle were removed, weighed, and counted for ${ }^{125} \mathrm{I}$ (RiaGamma 1271). Tumor-to-normal tissue ratios were calculated by dividing the ${ }^{125} \mathrm{I}$ counts per gram tumor by the ${ }^{125} \mathrm{I}$ counts per gram normal tissue.

\section{MNT subcellular localization}

Female DBA/2 mice bearing Cloudman melanoma S91 (M3 clone, transfected stably with green fluorescent protein [GFP] via copGFP gene) or C57 black female mice bearing B16-F1 melanoma were injected intravenously three times at 30-minute intervals with $150 \mathrm{mg} / \mathrm{kg}$ DTox-HMP-NLS$\alpha \mathrm{MSH}$ in $0.87-1 \mathrm{~mL}$ saline (depending on animal weight) with $50 \mu \mathrm{g} / \mathrm{mL}$ gentamicin. Three hours after the last injection, the mice were sacrificed and perfused with phosphatebuffered saline. Tumors and surrounding normal tissues were removed, embedded in GSV 1 tissue embedding medium (Slee Medical GmbH, Mainz, Germany) and snap-frozen in liquid nitrogen. The frozen tissue blocks were cut into $10 \mu \mathrm{m}$ sections using a Leica CM1510 cryotome (Leica, Wetzlar, Germany), fixed in acetone/methanol (2:3, v/v) mixture for 10 minutes at $-20^{\circ} \mathrm{C}$, air-dried, stained with primary rabbit anti-MNT antibodies (Ab), followed by staining with secondary goat antirabbit Ab conjugated with Alexa Fluor 555 (Invitrogen, Carlsbad, CA) then with tertiary donkey antigoat $\mathrm{Ab}$ conjugated with Alexa Fluor 555, and also with DAPI in order to visualize cell nuclei.

Likewise, male Balb/c ByJIco-nu/nu mice bearing A431 human epidermoid carcinoma xenografts were injected 
intravenously with $3 \mathrm{mg}$ of chlorin $\mathrm{e}_{6}$-DTox-HMP-NLS-EGF conjugate in $750 \mu \mathrm{L}$ of saline with $50 \mu \mathrm{g} / \mathrm{mL}$ gentamicin; a control group did not receive the conjugate. Three hours later, the mice in both groups were sacrificed, perfused with phosphate-buffered saline, and their tumors and surrounding normal tissues were removed. The specimens were embedded in Lowicryl K4M, sectioned at 2-3 $\mu \mathrm{m}$ using an LKB-3 microtome (LKB, Uppsala, Sweden), and stained as described above (tertiary Ab staining omitted).

Subcellular localization was investigated using an LSM 510 META NLO multiphoton laser scanning microscope (Carl Zeiss, Oberkochen, Germany) equipped with a Mai Tai broadband mode-locked Ti-sapphire laser (Spectra Physics $^{\circledR}$ ) with a $63 \times$ or $40 \times$ objective lens, NA 1.4 and 1.3 , respectively. Alexa Fluor 555 fluorescence was excited with a He-Ne laser (543 nm); DAPI fluorescence was two-photon excited with a Ti-sapphire laser $(800 \mathrm{~nm})$, and GFP fluorescence was excited with an Ar laser (458 nm). When evaluating A431 specimens, Alexa Fluor 555 fluorescence was separated from autofluorescence by analysis of fluorescence spectra within the 564-704 nm range using the microscope META system and a linear unmixing standard procedure. To calculate the percentage of fields with specific MNT signal in tumor and neighboring skin cells, nuclei and cytoplasm were defined by DAPI fluorescence and transmitted light images, respectively. At least 89 fields of approximately the same area were used for each point and the average Alexa Fluor 555 signal intensity was measured in each field. A signal was considered to be specific if it exceeded the intensity of fluorescence in $95 \%$ of the control field area (tissue sections processed in the same manner but obtained from control mice not receiving $\mathrm{MNT}$ ).

\section{In vivo efficacy}

\section{BI6-FI melanoma}

A total of $5 \times 10^{5}$ B16-F1 melanoma cells in $10 \mu \mathrm{L}$ Dulbecco's Modified Eagle Medium were inoculated subcutaneously into the depilated right hind flanks of female C57 black/6J mice. Four days later, mice were injected intravenously with either $27 \mu \mathrm{g}$ of bacteriochlorin $p$ coupled with $1 \mathrm{mg}$ DTox-HMP-NLS- $\alpha$ MSH in $500 \mu \mathrm{L}$ of saline containing $50 \mu \mathrm{g} / \mathrm{mL}$ gentamicin $(\mathrm{n}=5$; MNT-bacteriochlorin group) or $27 \mu \mathrm{g}$ of bacteriochlorin $p$ in $500 \mu \mathrm{L}$ of saline containing $50 \mu \mathrm{g} / \mathrm{mL}$ gentamicin ( $\mathrm{n}=5$; bacteriochlorin group); nine untreated mice served as controls. After 3 hours, the tumors were illuminated with a $400 \mathrm{~W}$ lamp (ELT) through an interference filter (transmittance maximum at $761 \mathrm{~nm}$ ), $380 \mathrm{~mW} / \mathrm{cm}^{2}$ fluence rate, and $360 \mathrm{~J} / \mathrm{cm}^{2}$ illumination dose. This injection/illumination scheme was repeated on days $6,8,11$, and 13 after melanoma cell inoculation.

\section{Cloudman S9I melanoma}

A total of $5 \times 10^{5}$ Cloudman S91 (clone M3) melanoma cells in $10 \mu \mathrm{L}$ of Hanks' solution were inoculated subcutaneously into the depilated right hind flanks of female DBA/2 mice. Three days later, the mice were injected intravenously with either $19 \mu \mathrm{g}$ of bacteriochlorin $p$ coupled with $1 \mathrm{mg}$ of DToxHMP-NLS- $\alpha$ MSH in $230 \mu \mathrm{L}$ of saline containing $50 \mu \mathrm{g} / \mathrm{mL}$ gentamicin ( $\mathrm{n}=5$, MNT-bacteriochlorin group) or $19 \mu \mathrm{g}$ of bacteriochlorin $p$ in $230 \mu \mathrm{L}$ of saline containing $50 \mu \mathrm{g} / \mathrm{mL}$ gentamicin ( $n=4$; bacteriochlorin group); eight untreated mice served as controls. After 3 hours, tumors were illuminated with a $400 \mathrm{~W}$ lamp (ELT) through an interference filter (transmittance maximum at $761 \mathrm{~nm}$ ), $38 \mathrm{~mW} / \mathrm{cm}^{2}$ fluence rate, and $36 \mathrm{~J} / \mathrm{cm}^{2}$ illumination dose. On days 4, 5, 6, and 7 after tumor cell inoculation, the MNT-bacteriochlorin group received $24 \mu \mathrm{g}$ of bacteriochlorin $p$ coupled with $1.2 \mathrm{mg}$ of DTox-HMP-NLS- $\alpha$ MSH in $280 \mu \mathrm{L}$ of saline containing $50 \mu \mathrm{g} / \mathrm{mL}$ gentamicin and the bacteriochlorin group received $24 \mu \mathrm{g}$ of bacteriochlorin $p$ in $280 \mu \mathrm{L}$ of saline containing $50 \mu \mathrm{g} / \mathrm{mL}$ gentamicin; 3 hours later, tumors were illuminated at $761 \mathrm{~nm}, 380 \mathrm{~mW} / \mathrm{cm}^{2}$ fluence rate, and $360 \mathrm{~J} / \mathrm{cm}^{2}$ illumination dose.

\section{Human A43 I epidermoid carcinoma}

A total of $1 \times 10^{6} \mathrm{~A} 431$ cells in $10 \mu \mathrm{L}$ of phosphate-buffered saline were inoculated subcutaneously into the right hind flanks of male Balb/c ByJIco-nu/nu mice. On days 3, 6, 8, 11,14 , and 20 , mice were injected intravenously with either $44 \mu \mathrm{g}$ chlorin $\mathrm{e}_{6}$ coupled with $3 \mathrm{mg}$ DTox-HMP-NLS-EGF in $750 \mu \mathrm{L}$ of saline containing $50 \mu \mathrm{g} / \mathrm{mL}$ gentamicin $(\mathrm{n}=8$; MNT-chlorin group) or $44 \mu \mathrm{g}$ of chlorin $\mathrm{e}_{6}$ in $500 \mu \mathrm{L}$ of saline containing $50 \mu \mathrm{g} / \mathrm{mL}$ gentamicin $(\mathrm{n}=10$; chlorin group); 11 untreated mice comprised the control group. After 3 hours, the tumors were illuminated with a laser beam (Biolitec AG, Jena, Germany) at $652 \mathrm{~nm}\left(80 \mathrm{~mW} / \mathrm{cm}^{2}\right.$ fluence rate and $48 \mathrm{~J} / \mathrm{cm}^{2}$ illumination dose for the first and second treatments; $100 \mathrm{~mW} / \mathrm{cm}^{2}$ fluence rate and $60 \mathrm{~J} / \mathrm{cm}^{2}$ illumination dose for later treatments).

\section{Tumor response}

Percentage of tumor growth inhibition was calculated as a normalized difference between the change in control and treated tumor volumes on the last day that all animals were alive in all treatment and control groups. ${ }^{19}$ Additional details are provided in the Supplementary data. 


\section{Statistical analysis}

Error bars represent the mean value \pm standard error of the mean (SEM). Statistical significance for tumor growth inhibition and survival studies was determined by the MannWhitney test; other analyses used Student's $t$-test. $P<0.05$ were considered to be statistically significant.

\section{Results MNT design}

Small-sized (mean hydrodynamic diameter $10.6 \pm 0.5 \mathrm{~nm}$, Figure 2A) specific multifunctional MNT demonstrated excellent results in enhancement of photodynamic effects of photosensitizers on cancer cell lines in vitro, but their action on tumors was not investigated up to this time. Such an approach has advantages when precise delivery of a relatively small number of molecules per cell is sufficient for a therapeutic effect. In this sense, use of photosensitizers is a convenient way for testing the approach in vivo. MNT DTox-HMP-NLS- $\alpha M S H$ and DTox-HMP-NLS-EGF were designed to facilitate four subcellular routing events, ie, receptor binding, endocytosis, endosomal escape, and nuclear import, by combining four functional modules from their $\mathrm{N}$-terminal to C-terminal ends (Figure 1). Functionality of all these modules was checked as previously described ${ }^{12,16,17}$ and confirmed. MNT were capable of specific interaction with targeted receptors, being overexpressed on tumor cells, and subsequent receptor-mediated endocytosis. ${ }^{12,16}$

At endosomal $\mathrm{pH}, \mathrm{MNT}$ embedded into the lipid bilayer and could self-assemble into circular structures ${ }^{16,17}$ (Figure 2B). Analyzing these specific structures, we estimated the mean height, width, and length of the MNT molecule as $5.3 \pm 0.4,9.0 \pm 0.9$, and $12.5 \pm 1.9 \mathrm{~nm}( \pm \mathrm{SEM})$, respectively. On the basis of these dimensions and a mean diameter of the circular structures of $43.1 \pm 1.2 \mathrm{~nm}$, the mean number of MNT molecules in these circular structures was calculated to be $11 \pm 2$. These structures formed pores, ${ }^{16,17}$ permitting escape of MNT into the hyaloplasm, ${ }^{12}$ where they can interact with importins. Finally, MNT interacted with the $\alpha / \beta$ importin heterodimer, mediating nuclear import with an affinity very close to that for the same NLS as a free oligopeptide. ${ }^{12,16}$

Murine melanomas (Cloudman S91, clone M3, and B16-F1 cell lines) as well as human epidermoid carcinoma A431 cells were chosen for treatment of experimental tumors overexpressing the $\alpha \mathrm{MSH}$ receptor and EGFR, respectively. MNT and their photosensitizer conjugates retained bioactivity after storage at $4^{\circ} \mathrm{C}$ or even after long-term storage in freeze-dried form at room temperature (see Supplementary data, Figures S1 and S2).

\section{MNT toxicity and immunogenicity}

C57 black/6J mice ( $n=3$, 4-week observation) tolerated the highest achievable intravenous dose of DTox-HMPNLS- $\alpha$ MSH (7.5 mg), slowly injected in $1.5 \mathrm{~mL}$ of saline with $50 \mu \mathrm{g} / \mathrm{mL}$ gentamicin; higher MNT doses could not be evaluated because of limitations in MNT solubility. C57 black/6J ( $\mathrm{n}=5$, 2-week observation) and Balb/c ByJIco-nu/ $n u(\mathrm{n}=8,4$-week observation) mice also tolerated multiple intravenous injections of $4 \times 2 \mathrm{mg}$ DTox-HMP-NLS- $\alpha M S H$ and $6 \times 3 \mathrm{mg}$ DTox-HMP-NLS-EGF, respectively, with time intervals of 2-3 days between doses. Intravenous administration of DTox-HMP-NLS-EGF to C57 black/6J at a dose of $4 \mathrm{mg}$ per mouse did not lead to significant changes in behavior or macroscopic organ changes, when compared with animals injected with the same volume of saline. In the microscopic study, the only significant change relative to the control group was a $30 \%$ reduction in the number of binuclear hepatocytes, which may indicate a decrease in liver proliferative capacity (data obtained in collaboration with Zenkova et al, manuscript in preparation). These data show that MNT are not toxic to mice when administered either as a single injection at the maximum achievable dose or when administered in multiple dose regimens.

Delayed-type hypersensitivity reactions are often used as a correlate of immune response to administered polypeptides. ${ }^{20}$ MNT administration induced slight delayed-type hypersensitivity in $\mathrm{C} 57$ black/6J mice injected with DToxHMP-NLS- $\alpha$ MSH (5.4\%), with the difference between experimental and control groups not being statistically significant. Generally, an increase over the control group of about $20 \%$ or more is considered to indicate an immunogenic response, ${ }^{21}$ suggesting a low degree of immunogenicity for this MNT.

\section{In vivo targeting evaluated with ${ }^{125}$-labeled MNT}

DTox-HMP-NLS- $\alpha M S H$ was labeled with ${ }^{125} \mathrm{I}$ using the $\mathrm{N}$-succinimidyl 3-[ $\left.{ }^{[25} \mathrm{I}\right]$ iodobenzoate reagent, a method that has been shown to decrease in vivo deiodination by up to two orders of magnitude compared with conventional electrophilic methods. ${ }^{18}$ The ${ }^{125}$ I-labeled DTox-HMP-NLS- $\alpha$ MSH was injected intravenously into $\mathrm{C} 57$ black/6J mice bearing mouse melanoma tumors derived from B16-F1 cells which express about 10,000 $\alpha \mathrm{MSH}$ receptors per cell, ${ }^{22}$ and the biodistribution of activity in different tissues was measured (see Supplementary data, Figure S3). The ratio of ${ }^{125}$ I activity in tumor tissue relative to that in skin and muscle was chosen as a metric for evaluating in vivo targeting because these 
tissues are in proximity to melanoma and their collateral damage from photodynamic therapy should be avoided.

As shown in Figure 3, the selectivity of ${ }^{125}$ I-labeled DTox-HMP-NLS- $\alpha$ MSH retention generally increases with time. Tumor selectivity tends to be higher with doses of MNT $\geq 200 \mu \mathrm{g}$, than with $11 \mu \mathrm{g}$. The optimal dose seen for targeting at 3 hours was $214 \mu \mathrm{g}$ for tumor:skin $(9.8 \pm 1.8)$ and $850 \mu \mathrm{g}$ for tumor:muscle $(13.4 \pm 1.7)$ with a slightly higher tumor:muscle ratio than tumor:skin ratio, presumably reflecting the presence of melanocytes which express $\alpha \mathrm{MSH}$ receptors in normal skin. ${ }^{23}$ It is worth noting that the maximum tumor:skin ratio determined for MNT in this work is 3-8 times higher than those reported for free photosensitizers in this murine melanoma model. ${ }^{24-26}$

Based on these data demonstrating that tumor selectivity generally increases (Figure 3) while tumor accumulation rapidly decreases with time (dropping by more than $90 \%$ from 3 to 15 hours, see Supplementary data, Figure S4), we had chosen a time interval of 3 hours as a "happy medium" of significant tumor accumulation and selectivity rates for subsequent distribution and therapeutic experiments.

\section{In vivo targeting evaluated by immunofluorescence microscopy}

DTox-HMP-NLS- $\alpha$ MSH was injected intravenously into DBA/2 mice bearing Cloudman S91 melanoma, which express about $5000 \alpha \mathrm{MSH}$ receptors per cell ${ }^{22}$ and into C57 black/6J mice bearing B16-F1 mouse melanoma expressing about 10,000 $\alpha \mathrm{MSH}$ receptors per cell. ${ }^{22}$ Preferential tumor

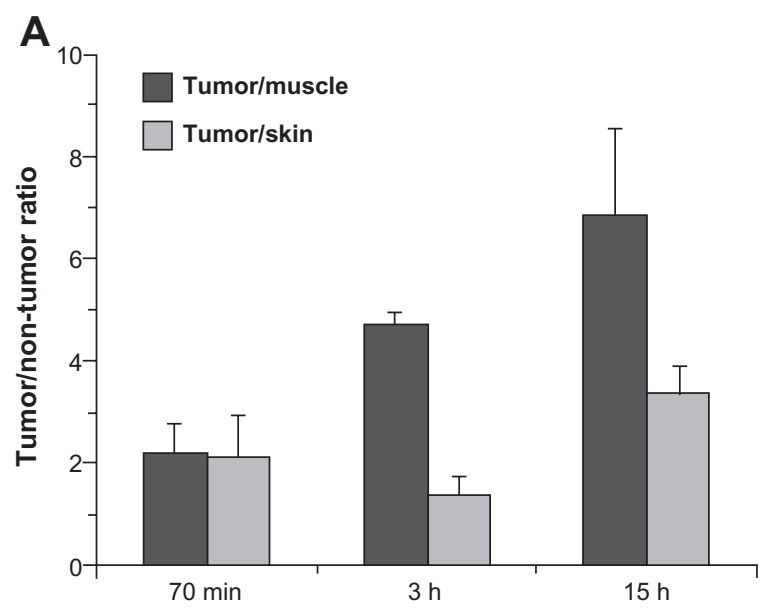

Time after iv injection of ${ }^{125}$ |-DTox-HMP-NLS- $\alpha M S H$ accumulation of MNT was observed at 3 hours after injection, which was distinguished from surrounding nontumor tissue by GFP fluorescence of transfected Cloudman S91 melanoma cells (Figure 4A-D). Moreover, comparison of MNT to DAPI staining suggested that a considerable fraction of MNT accumulation in both B16-F1 and Cloudman S91 melanoma cells occurred in the cell nuclei (Figure 5D-I). The percentage of fields exhibiting an MNT signal in nuclei and cytoplasm of tumor and proximal skin cells was also evaluated. As shown in Figure 4E, more than $80 \%$ and nearly $100 \%$ of fields in melanoma had an MNT signal in the nuclei and cytoplasm, respectively, compared with values of $<40 \%$ in skin. Because MNT internalization and transport to nuclei via cytoplasm is going on from outside continuously, we can only observe a "snapshot" of intracellular distribution of the MNT, with a significant part caught on its way (eg, in the cytoplasm) to the target compartment. Similar results were obtained after intravenous injection of DTox-HMP-NLS-EGF into Balb/c ByJIco-nu/nu mice bearing EGFR-expressing human epidermoid carcinoma A431 xenografts, ie, accumulation of MNT in tumor cells with evidence for localization within the cell nuclei (Figure 5A-C). These experiments confirm that MNT can be designed to undergo transport from the blood pool to the intended subcellular target in receptor-expressing tumor cells in vivo.

\section{In vivo MNT antitumor efficacy}

In order to evaluate the potential utility of MNT for enhancing the therapeutic efficacy of a drug that requires localization within the cell nucleus to be effective, photodynamic

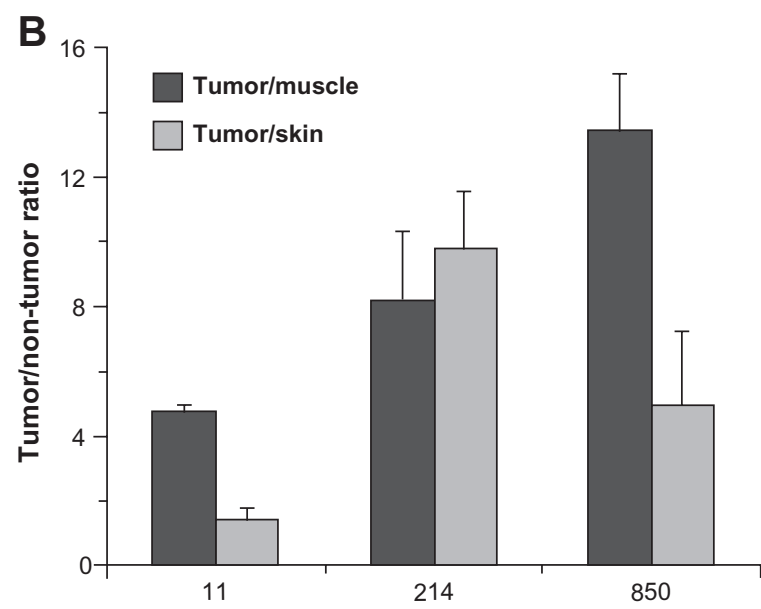

125|-DTox-HMP-NLS- $\alpha$ MSH, $\mu$ g/mouse

Figure 3 Tumor-to-tissue ratios of ${ }^{125}$ I after intravenous injection of ${ }^{125}$ /-labeled DTox-HMP-NLS- $\alpha$ MSH in BI6-FI melanoma-bearing C57 black/6) mice. (A) Effect of time, II $\mu \mathrm{g}$ MNT dose. (B) Effect of MNT dose, 3 hours post injection.

Note: Bars represent the mean $\pm \operatorname{SEM}(n=3)$.

Abbreviations: MNT, modular nanotransporter; DTox, translocation domain of diphtheria toxin; HMP, Escherichia coli hemoglobin-like protein; NLS, nuclear localization sequence; SEM, standard error of mean; iv, intravenously. 

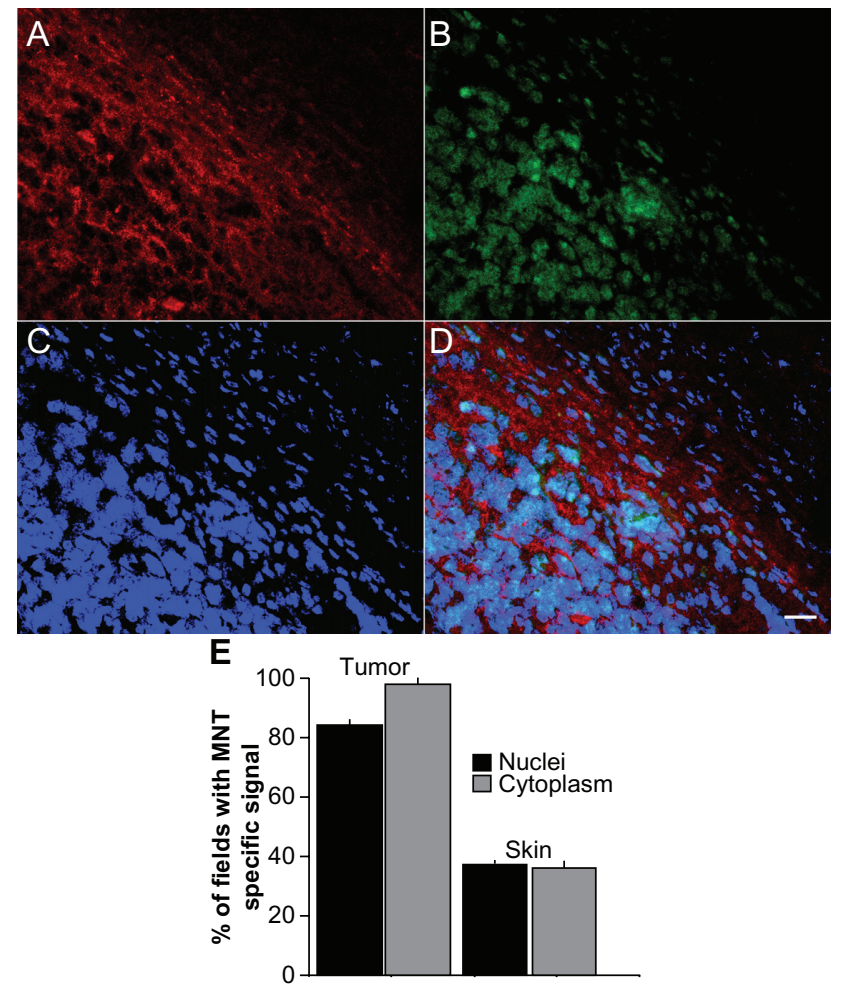

Figure 4 Immunofluorescence analysis of in vivo distribution in tumor and neighboring tissue, and subcellular localization of MNT 3 hours after intravenous injection in mice. $10 \mu \mathrm{m}$ tissue sections from DBA/2 mice bearing murine Cloudman melanoma S9/ transfected with green fluorescent protein receiving DTox-HMP-NLS- $\alpha M S H$. (A-D) Tumor and surrounding tissue section (40x objective lens). (A)Alexa Fluor 555 staining for MNT (red); (B) green fluorescent protein from tumor cells (green); (C) DAPI staining of cell nuclei (blue); (D) overlay of A, B, and C. (E) Percentage of fields ( \pm SEM) with specific MNT signal in nuclei and cytoplasm of tumor and neighboring skin cells. Notes: Bars represent the mean \pm SEM ( $n \geq 89$ ); scale bar, $20 \mu \mathrm{m}$.

Abbreviations: MNT, modular nanotransporter; DTox, translocation domain of diphtheria toxin; HMP, the Escherichia coli hemoglobin-like protein; NLS, nuclear localization sequence; $\alpha M S H, \alpha$-melanocyte stimulating hormone; SEM, standard error of mean; DAPI, 4',6-diamidino-2-phenylindole.

therapy studies were performed in three different subcutaneous murine tumor models, with therapy initiated 3 hours after injection of the photosensitizer. The first experiment was performed in C57 black/6J mice with B16-F1 melanoma. An $89 \%$ inhibition of tumor growth was observed with the bacteriochlorin $p$-DTox-HMP-NLS- $\alpha$ MSH conjugate, while no significant effect was seen with free bacteriochlorin $p$ (Figure 6A). Median survival for mice receiving the photosensitizer-MNT conjugate was $32.0 \pm 1.3$ days, compared with $17.0 \pm 1.5$ days for the control group and $20.0 \pm 5.5$ days for the bacteriochlorin $p$ group (Figure 6B). The difference in survival between photosensitizer-MNT and each of two control groups was significant $(P<0.01)$. The second experiment utilized DBA/2 mice with Cloudman S91 melanoma, and a $98 \%$ inhibition in tumor growth was observed with the bacteriochlorin $p$-DTox-HMP-NLS- $\alpha$ MSH conjugate
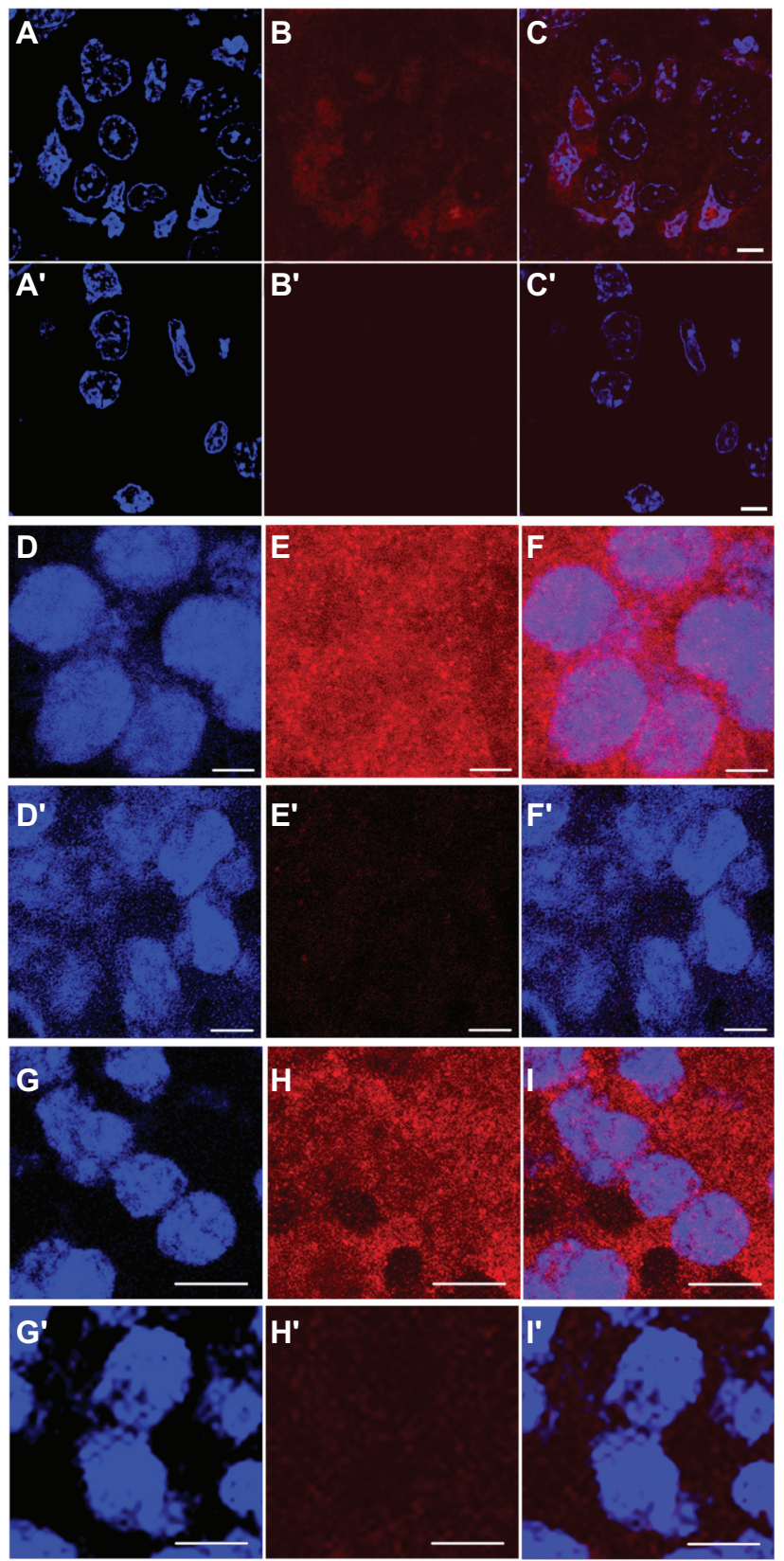

Figure 5 Immunofluorescence analysis of in vivo subcellular localization of MNT 3 hours after intravenous injection in mice. (A-C) 2-3 $\mu$ m tumor section (63x objective lens) from Balb/c Byllco-nu/nu mouse bearing human A43I epidermoid carcinoma 3 hours after intravenous injection of chlorin $\mathrm{e}_{6}$-DTox-HMPNLS-EGF, $\left(\mathbf{A}^{\prime}-\mathbf{C}^{\prime}\right)$ the same, but from the control mouse that was injected with saline. (D-F) $10 \mu \mathrm{m}$ tumor section (63× objective lens) from C57 black/6J mice bearing murine BI6-FI melanoma injected with DTox-HMP-NLS- $\alpha M S H,\left(\mathbf{D}^{\prime}-\mathbf{F}^{\prime}\right)$ the same, but from the control mouse that was injected with saline. (G-I) $10 \mu \mathrm{m}$ tumor section (63× objective lens) from DBA/2 mice bearing murine Cloudman melanoma S9I injected with DTox-HMP-NLS- $\alpha M S H,\left(\mathbf{G}^{\prime}-\mathbf{I}^{\prime}\right)$ the same, but from the control mouse that was injected with saline. (A), ( $\left.\mathbf{A}^{\prime}\right),(\mathbf{D}),\left(\mathbf{D}^{\prime}\right),(\mathbf{G}),\left(\mathbf{G}^{\prime}\right)$ DAPI staining of cell nuclei (blue); (B), ( $\left.\mathbf{B}^{\prime}\right),(\mathbf{E}),\left(\mathbf{E}^{\prime}\right),(\mathbf{H}),\left(\mathbf{H}^{\prime}\right)$ Alexa Fluor 555 staining for MNT (red); (C), ( $\left.\mathbf{C}^{\prime}\right),(\mathbf{F}),\left(\mathbf{F}^{\prime}\right),(\mathbf{I}),\left(\mathbf{I}^{\prime}\right)$ overlay of cell nuclei fluorescence (blue) and MNT fluorescence (red). Scale bar $5 \mu \mathrm{m}$ for $(\mathbf{A}-\mathbf{F})$ and for $\left(\mathbf{A}^{\prime}-\mathbf{F}^{\prime}\right)$; scale bar $10 \mu \mathrm{m}$ for $(\mathbf{G}-\mathbf{I})$ and for $\left(\mathbf{G}^{\prime}-\mathbf{I}^{\prime}\right)$.

Abbreviations: MNT, modular nanotransporter; DTox, translocation domain of diphtheria toxin; HMP, the Escherichia coli hemoglobin-like protein; NLS, nuclear localization sequence; EGF, epidermal growth factor; $\alpha \mathrm{MSH}, \alpha$-melanocyte stimulating hormone; SEM, standard error of mean; DAPI, 4',6-diamidino-2-phenylindole. 
A

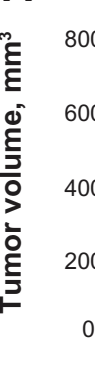

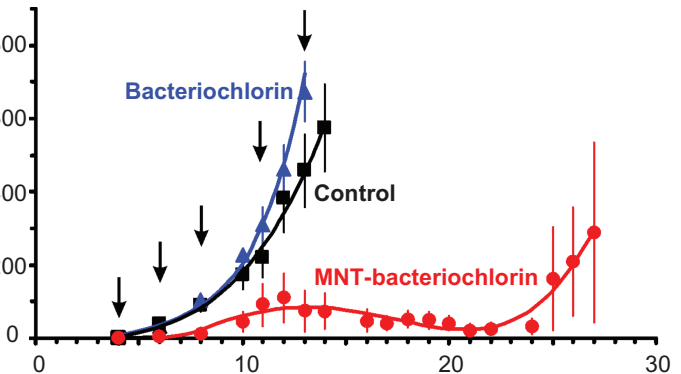

Time after inoculation, days

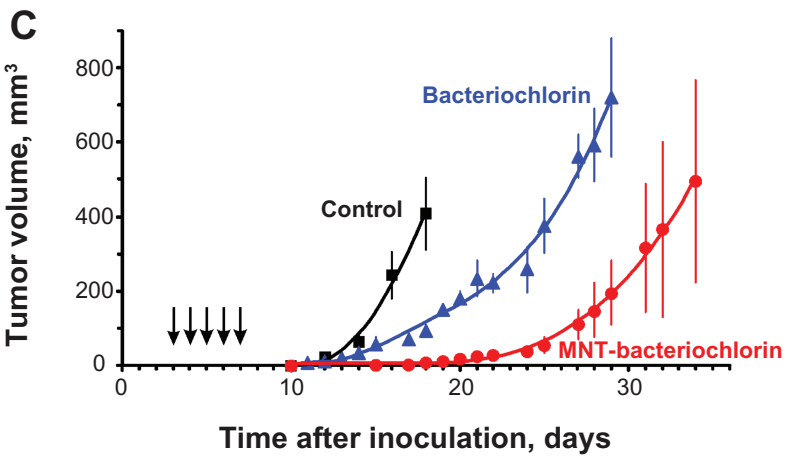

B

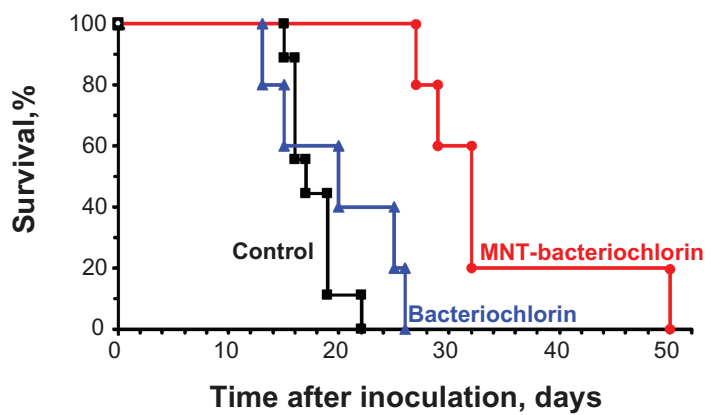

D

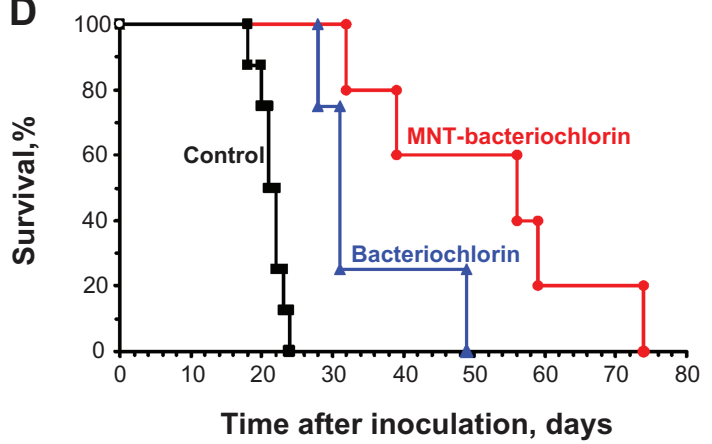

Figure 6 Comparative efficacy of photodynamic therapy with bacteriochlorin $p$ conjugated with DTox-HMP-NLS- $\alpha$ MSH MNT and free bacteriochlorin $p$. (A-B) C57 black/6J mice with subcutaneous BI6-FI murine melanoma. (A) Tumor growth, mean \pm SEM; average tumor volumes are shown up to the last day when all animals were alive. (B) Kaplan-Meier survival curve. (C-D) DBA/2 mice with subcutaneous Cloudman S9I murine melanoma. (C) Tumor growth, mean \pm SEM; average tumor volumes are shown up to the last day when all animals were alive. (D) Kaplan-Meier survival curve.

Notes: Arrows indicate injection and illumination cycles; bars represent the mean \pm SEM.

Abbreviations: MNT, modular nanotransporter; DTox, translocation domain of diphtheria toxin; HMP, the Escherichia coli hemoglobin-like protein; NLS, nuclear localization sequence; $\alpha M S H, \alpha$-melanocyte stimulating hormone; SEM, standard error of the mean.

relative to controls $(93 \%$ relative to free photosensitizers, Figure 6C). Median survival for mice receiving the photosensitizer-MNT conjugate was $56.0 \pm 18.6$ days compared with $21.0 \pm 0.7$ days for the control group and $31.0 \pm 1.3$ days for the bacteriochlorin $p$ group (Figure 6D). The third experiment was performed with chlorin $\mathrm{e}_{6}$-DTox-HMP-NLS-EGF in Balb/c ByJIco-nu/nu mice with A431 human epidermoid carcinoma xenografts. A $98 \%$ inhibition in tumor growth was observed with the chlorin $\mathrm{e}_{6}$-DTox-HMP-NLS-EGF conjugate relative to controls ( $94 \%$ relative to free photosensitizers, Figure 7A). Median survival for mice in the control group was $20.0 \pm 0.4$ days, with all animals succumbing by
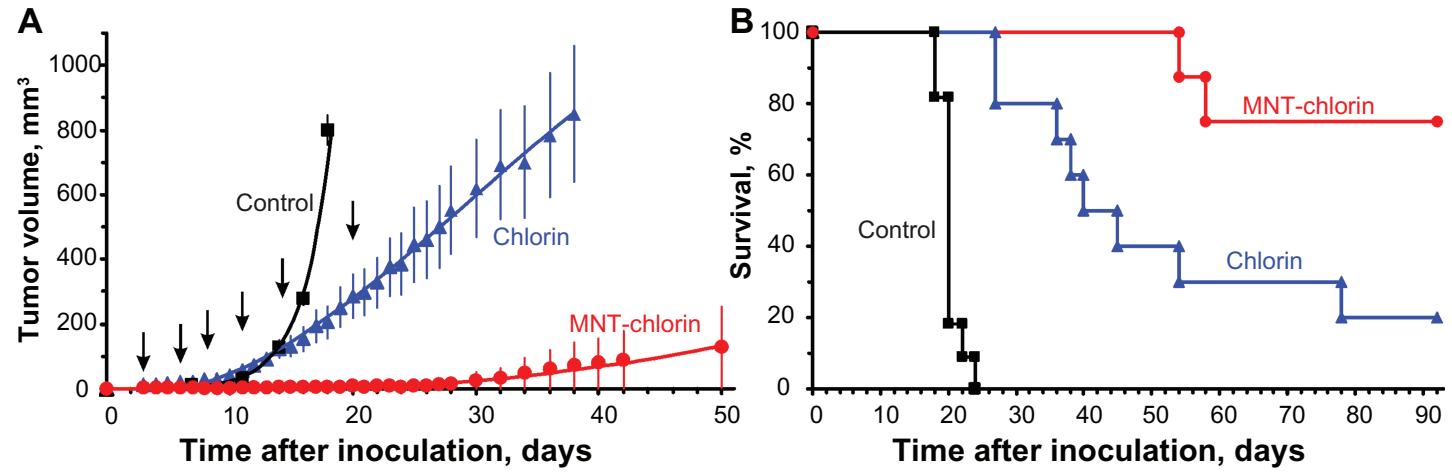

Figure 7 Photodynamic therapy with chlorin e conjugated with DTox-HMP-NLS-EGF MNT inhibits A43I human epidermoid carcinoma growth and enhances survival of tumor-bearing Balb/c Byllco-nu/nu mice compared with free chlorin $\mathrm{e}_{6^{\circ}}$ (A) A43I tumor growth, mean \pm SEM; average tumor volumes are shown up to the last day when all animals were alive. (B) Kaplan-Meier survival curve.

Notes: Arrows indicate injection and illumination cycles; bars represent the mean \pm SEM.

Abbreviations: MNT, modular nanotransporter; DTox, translocation domain of diphtheria toxin; HMP, Escherichia coli hemoglobin-like protein; NLS, nuclear localization sequence; EGF, epidermal growth factor; SEM, standard error of mean. 
24 days (Figure 7B). In contrast, 75\% of animals remained alive at the end of the 92-day observation period in the chlorin $\mathrm{e}_{6}$-DTox-HMP-NLS-EGF group compared with $20 \%$ in the chlorin $\mathrm{e}_{6}$ group.

\section{Discussion}

Multicomponent systems consisting of modified biological molecules or their parts, ${ }^{27}$ biological particles or their parts, ${ }^{28}$ and even subcellular structure ${ }^{29}$ are often used as delivery systems. In this study, we describe the in vivo working polypeptide-based, multifunctional platform for targeted delivery of short-range highly cytotoxic therapeutics to the most vulnerable compartment of the tumor cell. We demonstrate that selective accumulation in tumors, with preferential accumulation in cancer cell nuclei but not in adjacent normal tissue, enhances the therapeutic efficacy of photosensitizers, a type of drug that requires localization within the cell nucleus to be effective. In designing a nanosized multifunctional vehicle for achieving efficient delivery to cell nuclei in cancer cells, the first objective was to optimize delivery to the tumor and the second was to facilitate intracellular transport to the nucleus. With regard to the former, the tumor uptake of, eg, nanoparticles, exploits the presence of 200-1200 nm pores present in tumor vascular endothelium ${ }^{30}$ via the enhanced permeability and retention effect. However, this generally occurs at the expense of being able to improve specificity through the addition of a receptor-addressable targeting element. ${ }^{31-34}$ Instead, given that tumor permeability and extravasation increases with decreasing molecular size, we decided to assemble an artificial multifunctional device genetically with a controllable molecular weight rather than utilize a particle scaffold with multiple functional elements decorating its surface. One cannot exclude the possibility that the enhanced permeability and retention effect can play a role when MNT-photosensitizer conjugates are administered intravenously. However, it should be noted that the enhanced permeability and retention effect can also be observed with free photosensitizers; more than $90 \%$ of them are immediately taken up by different blood proteins and lipoproteins, mainly by low-density lipoproteins, highdensity lipoproteins, and albumin. ${ }^{35}$ In tumor tissue, where extracellular $\mathrm{pH}$ is lower than that of normal tissue, chlorin $\mathrm{e}_{6}$ binds to low-density lipoproteins which are considered to be effective photosensitizer delivery vehicles, ${ }^{36}$ and significantly better than at neutral $\mathrm{pH} .{ }^{37,38}$ Thus, the injected photosensitizers exist in blood mainly in a protein-bound state and their behavior is governed ${ }^{37}$ by the macromolecules and macromolecular complexes which bind them. It has been shown that the enhanced permeability and retention effect can be observed with macromolecules having an apparent molecular size larger than $40-800 \mathrm{kDa} .{ }^{39}$ In comparison, the molecular weight of our MNT is approximately $70 \mathrm{kDa}$, and that of low-density lipoprotein is about $3000 \mathrm{kDa} .{ }^{40}$ Leunig et al, ${ }^{41}$ who investigated tumor accumulation of different porphyrin-like photosensitizers, showed that the enhanced permeability and retention effect appears to be the most probable reason for the tumor selectivity of this type of photosensitizer. Therefore, qualitatively, free photosensitizer in tumor vessels and photosensitizer transported by MNT may be considered as similar in terms of enhanced permeability and retention effect, and perhaps even more favorable for the free photosensitizer.

Selective delivery of a drug to the cell nucleus is dependent on at least three design elements, ie, a NLS, a size compatible with passage through pores in the nuclear membrane, and a means of achieving specific binding to the targeted cell population. A variety of NLS, including the one used in this study, have been shown to deliver drugs efficiently to the cell nucleus via binding to importins present in the cytoplasm. ${ }^{42}$ However, even after binding of a molecule to NLS, the size of the openings in the nuclear pore complex only increases from $8-10 \mathrm{~nm}$ to about $40 \mathrm{~nm},{ }^{43,44}$ restricting nuclear entry to larger carrier systems. Another limitation of NLS-mediated delivery is that it lacks tumor specificity. One approach that has been investigated to circumvent this problem is to couple multiple NLS to internalizing antibodies. ${ }^{45,46}$ Although NLS conjugation was shown to enhance nuclear localization, the majority of the activity was found in other cellular compartments. A possible contributing factor to these observations is sequestration of the NLS-modified antibody in endosomes after receptor-mediated endocytosis, which could lead to proteolytic degradation of the conjugate and/or prevent significant interaction with nuclear transport receptors present in the cytoplasm.

For this reason, we believe that an important design element of these MNT is the provision of an endosome escape pathway, thereby increasing the probability of NLS contact with cytoplasmic importins and facilitating nuclear translocation. The translocation domain of DTox was selected for this purpose and previous studies have shown that MNT containing the DTox sequence resulted in the creation of pores in lipid bilayers at endosomal/lysosomal $\mathrm{pH} .{ }^{16,17}$

In vitro, it is possible to separate the two processes involved, ${ }^{16}$ ie, MNT penetration into the cell cytoplasm and subsequent MNT nuclear accumulation in the nuclei. The cells can be additionally incubated without MNT after 
incubation with MNT, thus permitting cytoplasmic MNT to enter into the nuclei. However, such a method cannot be used in vivo. One needs to make frozen sections in the situation where the MNT has gone from the blood pool and intercellular space to the target cells, where the MNT is presumed to pass from the cell membrane to the cytoplasm, and finally undergo translocation to the cell nuclei. Moreover, one must utilize a method with sufficient sensitivity to detect diminishing quantities of the MNT. Fortunately, such a favorable concurrence of circumstances can be seen in Figure 5A-C, which depicts predominantly nuclear MNT accumulation. In other cases (Figure 5D-F, Figure 5G-I), we obtained images showing that MNT is in the nuclei and also in the cytoplasm. Nevertheless, all the images are consistent with nuclear targeting of MNT.

Perhaps the most relevant metric for evaluating the potential utility of MNT for transport of a drug from the blood pool to the nuclei of target cell populations is to determine the effect of MNT conjugation on the therapeutic efficacy of a drug that is cytotoxic only when localized in the cell nucleus. Although Auger electron emitting radionuclides ultimately might be the best method for eventual clinical application of MNT, they also emit other radiation with multicellular ranges. Instead, we evaluated MNT in the context of photodynamic therapy because the cytotoxic reactive oxygen species generated upon photoactivation have a radius of action of less than $0.02 \mu \mathrm{m}$ and their effects in tumor tissue can be switched on and off nearly instantaneously with light of an appropriate wavelength. ${ }^{47} \mathrm{~A}$ time interval of 3 hours between photosensitizer-MNT or photosensitizer administration and tumor illumination was selected on the basis of previous studies using chlorin $\mathrm{e}_{6}$ and its derivatives for photodynamic therapy ${ }^{48}$ and our data on tumor-specific accumulation kinetics of MNT. In the three in vivo efficacy experiments, the nature of the tumor, receptor target, photosensitizer and MNT varied, and differences in therapeutic effectiveness of the photosensitizer-MNT (and also the free photosensitizer) were observed.

Treatment of melanoma by photodynamic therapy is hindered substantially by almost complete absorption of light by melanin. ${ }^{49}$ For this reason, the therapeutic efficacy of DTox-HMP-NLS- $\alpha$ MSH in the two murine melanoma models in tandem with bacteriochlorin $p$, a photosensitizer with an absorption peak at a wavelength $(761 \mathrm{~nm})$ where light penetration is better, was estimated. Furthermore, in vitro studies have shown that coupling this MNT to bacteriochlorin $p$ resulted in a more than 200 -fold enhancement in cytotoxicity compared with free photosensitizer. ${ }^{12}$ Particularly given the difficulties inherent in photodynamic therapy for melanoma, the two-fold increase in median survival and significant inhibition in tumor growth obtained with the bacteriochlorin $p$-DTox-HMP-NLS- $\alpha$ MSH conjugate in both the B16-F1 and Cloudman S91 models is very encouraging. Consistent with its less pigmented nature, offering the possibility of higher light penetration, longer median survivals for photosensitizer-MNT (and free photosensitizer) were seen in animals with Cloudman S91 melanoma. However, it should be noted that the average number of $\alpha \mathrm{MSH}$ receptors on B16-F1 cells in vitro is about twice that reported for Cloudman S91 cells. ${ }^{22}$

Photodynamic therapy was also performed with chlorin $\mathrm{e}_{6}$-DTox-HMP-NLS-EGF in athymic mice with A431 human epidermoid carcinoma xenografts in order to evaluate the therapeutic response obtainable with an MNT containing a different ligand module and in a setting less compromised by light absorption. The A431 xenograft is not pigmented and this property permits usage of photosensitizers absorbing light at a shorter wavelength (664 $\mathrm{nm}$ for chlorin $\mathrm{e}_{6}$ in phosphate-buffered saline) than bacteriochlorin $p$. Moreover, the average number of EGFR on the A431 cell line (about $10^{6}$ ) is at least 100 times higher than the number of $\alpha \mathrm{MSH}$ receptors on either the B16-F1 or Cloudman S91 melanoma cell lines, which could facilitate selective MNT binding to tumor. Finally, in vitro studies have shown that chlorin $\mathrm{e}_{6}$-DTox-HMP-NLS-EGF had a 3000 times higher efficacy compared with free photosensitizer; ${ }^{16}$ likewise, DTox-HMPNLS-EGF labeled with the $\alpha$-particle emitter ${ }^{211}$ At was significantly more cytotoxic than free ${ }^{211} \mathrm{At} .{ }^{50}$ Consistent with being the most favorable setting studied for receptor-targeted photodynamic therapy, the results obtained in terms of tumor growth delay and survival prolongation were the most striking, with $75 \%$ of animals receiving chlorin $e_{6}$-DTox-HMPNLS-EGF remaining without growing tumor at the end of the 3-month observation period.

\section{Conclusion}

In summary, this study provides the first in vivo evidence that MNT can selectively deliver drugs to the nuclei of tumor cells expressing a targeted receptor. MNT can improve specificity of drugs that ultimately can result in decreased side effects for patients, which is the main advantage and goal of nanomedicine. ${ }^{51}$ Moreover, delivery of drugs requiring nuclear transport to have a meaningful cytotoxic effect can be enhanced significantly through MNT-mediated delivery in vivo. In addition, preliminary studies suggest that MNT possess low toxicity and immunogenicity, as well as the 
practical advantages of being a nanoscale delivery system, including ease of production, long-term stability, and uniformity of physiochemical properties. Most of the " ... desired characteristics for a nanoparticle drug delivery platform ..."52 can be ascribed to MNT, ie, small size, stability under physiological conditions, inherently nontoxic materials and degradation products, moderate lifetime in the circulatory system (half-life about 45 minutes in mice for MNT similar to those described here; our unpublished data), a trigger mechanism for release into the hyaloplasm from acidifying endosomes, and specific cellular and subcellular targeting. Further, compared with most nanoscale delivery systems, MNT possess the essential combination of three functional modules, designed to provide step-by-step specific delivery from the surface of the target cell to its nucleus. As already mentioned, NLS, which is necessary to achieve entry of a particle/macromolecule into the interphase nucleus, can increase the size of the opening in the nuclear pore complex from only $8-10 \mathrm{~nm}$ to about $40 \mathrm{~nm}$, which restricts nuclear entry of larger carrier systems, including most liposomes and nanoparticles. This is one of the reasons for using MNT to achieve intranuclear delivery of drugs. Also, among the other potential advantages of MNT, one can mention their uniformity in size and composition. Finally, MNT offer the possibility of long-term storage, favorably distinguishing MNT from those nanoparticle systems that require preparation a relatively short time prior to use. ${ }^{53,54}$ Finally, because of the modular nature of MNT design, one could envisage utilizing this platform to generate personalized therapeutics by tailoring the ligand and drug profiles to the characteristics of individual patients.

\section{Acknowledgments}

This work was supported in part by a Dutch-Russian Scientific Cooperation grant (047.017.025), a National Institutes of Health grant (NS20023), RF State contract 16.512.12.2004, and by a Russian Foundation for Basic Research grant (10-04-01037-a). Access to instrumentation from the Center of Collective Usage, Institute of Gene Biology, is gratefully acknowledged. We thank G Baranova (Institute of Agricultural Biotechnology, Moscow) for help with histological preparations, N Shevkun (Moscow State University) for assistance with animal studies, D Tsarev (Moscow State University) for help with radioiodination, and S Lukyanov (Institute of Bioorganic Chemistry, Moscow) for the GFP-transfected M3 cells. The paper is dedicated to the memory of PV Gulak, our colleague and friend, who made a significant contribution to this work.
Supplementary data are available, including evaluation of MNT functionality after freeze drying, MNT toxicity results, in vivo ${ }^{125}$ I-labeled MNT tissue distribution and tumor uptake kinetics, and an additional Materials and Methods section for delayed-type hypersensitivity reaction and tumor response calculations.

\section{Disclosure}

The authors report no conflicts of interest in this work.

\section{References}

1. Davis ME, Chen ZG, Shin DM. Nanoparticle therapeutics: an emerging treatment modality for cancer. Nat Rev Drug Discov. 2008;7(9):771-782.

2. Jain RK, Stylianopoulos T. Delivering nanomedicine to solid tumors. Nat Rev Clin Oncol. 2010;7(11):653-664.

3. Bast RC, Zalutsky MR, Kreitman RJ, Frankel AE. Monoclonal serotherapy. In: Hong WK, Bast RC, Hait WN, et al, editors. Cancer Medicine. 8th ed. Ontario, Canada; 2010.

4. Kenanova V, Olafsen T, Williams LE, et al. Radioiodinated versus radiometal-labeled anticarcinoembryonic antigen single-chain $\mathrm{Fv}-\mathrm{Fc}$ antibody fragments: optimal pharmacokinetics for therapy. Cancer Res. 2007;67(2):718-726.

5. Choi CHJ, Alabi CA, Webster P, Davis ME. Mechanism of active targeting in solid tumors with transferrin-containing gold nanoparticles. Proc Natl Acad Sci U S A. 2010;107(3):1235-1240.

6. Reubi JC. Peptide receptors as molecular targets for cancer diagnosis and therapy. Endocr Rev. 2003;24(4):389-427.

7. Farokhzad OC, Cheng J, Teply BA, et al. Targeted nanoparticle-aptamer bioconjugates for cancer chemotherapy in vivo. Proc Nat Acad Sci U SA. 2006;103(16):6315-6320.

8. Hillaireau H, Couvreur P. Nanocarriers' entry into the cell: relevance to drug delivery. Cell Mol Life Sci. 2009;66(17):2873-2896.

9. Verma S, Watt GM, Mai Z, Hasan T. Strategies for enhanced photodynamic therapy effects. Photochem Photobiol. 2007;83(5):996-1005.

10. Reilly RM, Kassis A. Targeted auger electron radiotherapy of malignancies. In: Reilly RM, editor. Monoclonal Antibody and Peptide-Targeted Radiotherapy of Cancer. Hoboken, NJ: Wiley and Sons; 2010.

11. Akhlynina TV, Jans DA, Rosenkranz AA, et al. Nuclear targeting of chlorin $\mathrm{e}_{6}$ enhances its photosensitizing activity. J Biol Chem. 1997; 272(33):20328-20331.

12. Rosenkranz AA, Lunin VG, Gulak PV, et al. Recombinant modular transporters for cell-specific nuclear delivery of locally acting drugs enhance photosensitizer activity. FASEB J. 2003;17(9):1121-1123.

13. Sobolev AS. Modular transporters for subcellular cell-specific targeting of antitumor drugs. BioEssays. 2008;30(3):278-287.

14. Salazar-Onfray F, López M, Lundqvist A, et al. Tissue distribution and differential expression of melanocortin 1 receptor; a malignant melanoma marker. Br J Cancer. 2002;87(4):414-422.

15. Martinelli E, De Palma R, Orditura M, De Vita F, Ciardiello F. Anti-epidermal growth factor monoclonal antibodies in cancer therapy. Clin Exper Immunol. 2009;158(1):1-9.

16. Gilyazova DG, Rosenkranz AA, Gulak PV, et al. Targeting cancer cells by novel engineered modular transporters. Cancer Res. 2006;66(21): 10534-10540.

17. Khramtsov YV, Rokitskaya TI, Rosenkranz AA, et al. Modular drug transporters with diphtheria toxin translocation domain form edged holes in lipid membranes. J Control Release. 2008;128(3): 241-247.

18. Vaidyanathan G, Zalutsky MR. Preparation of N-succinimidyl 3-[*I] Iodobenzoate: an agent for the indirect radioiodination of proteins. Nat Protoc. 2006;1(2):707-713. 
19. Emanuel S, Rugg CA, Gruninger RH, et al. The in vitro and in vivo effects of JNJ-7706621: a dual inhibitor of cyclin-dependent kinases and aurora kinases. Cancer Res. 2005;65(19):9038-9046.

20. Kublin JG, Lowitt MH, Hamilton RG, et al. Delayed-type hypersensitivity in volunteers immunized with a synthetic multi-antigen peptide vaccine (Pfcs-MAP1 NYU) against Plasmodium falciparum sporozoites. Vaccine. 2002;20(13-14):1853-1861.

21. Omata Y, Kamiya H, Kano R, Kobayashi Y, Maeda R, Saito A. Footpad reaction induced by Neospora caninum tachyzoite extract in infected BALB/C mice. Vet Parasitol. 2006;139(1-3):102-108.

22. Siegrist W, Solca F, Stutz S, et al. Characterization of receptors for $\alpha$-melanocyte-stimulating hormone on human melanoma cells. Cancer Res. 1989;49(22):6352-6358.

23. Wikberg JE. Melanocortin receptors: perspectives for novel drugs. Eur J Pharmacol. 1999;375(1-3):295-310.

24. Woodburn KW, Fan Q, Kessel D, Luo Y, Young SW. Photodynamic therapy of B16F10 murine melanoma with lutetium texaphyrin. J Invest Dermatol. 1998;110(5):746-751.

25. Fabris C, Vicente MG, Hao E, et al. Tumour-localizing and photosensitising properties of mesotetra(4-nidocarboranylphenyl)porphyrin (H2TCP). J Photochem Photobiol B. 2007;89(2-3):131-138.

26. Jori G, Soncin M, Friso E, et al. A novel boronated-porphyrin as a radio-sensitizing agent for boron neutron capture therapy of tumours: in vitro and in vivo studies. Appl Radiat Isotopes. 2009;67(7-8 Suppl): S321-S324.

27. Simnick AJ, Valencia CA, Liu R, Chilkoti A. Morphing low-affinity ligands into high-avidity nanoparticles by thermally triggered selfassembly of a genetically encoded polymer. ACS Nano. 2010;4(4) 2217-2227.

28. Xiao F, Demeler B, Guo P. Assembly mechanism of the sixty-subunit nanoparticles via interaction of RNA with the reengineered protein connector of Phi29 DNA-packaging motor. ACS Nano. 2010;4(6): 3293-3301.

29. Sharma S, Rasool HI, Palanisamy V, et al. Structural-mechanical characterization of nanoparticle exosomes in human saliva, using correlative AFM, FESEM, and force spectroscopy. ACS Nano. 2010;4(4): 1921-1926.

30. Hobbs SK, Monsky WL, Yuan F, et al. Regulation of transport pathways in tumor vessels: role of tumor type and microenvironment. Proc Natl Acad Sci USA. 1998;95(8):4607-4612.

31. Kirpotin DB, Drummond DC, Shao Y, et al. Antibody targeting of longcirculating lipidic nanoparticles does not increase tumor localization but does increase internalization in animal models. Cancer Res. 2006; 66(13):6732-6740.

32. Bartlett DW, Su H, Hildebrandt IJ, Weber WA, Davis ME. Impact of tumor specific targeting on the biodistribution and efficacy of sirna nanoparticles measured by multimodality in vivo imaging. Proc Natl Acad Sci US A. 2007;104(39):15549-15554.

33. Schmidt MM, Wittrup KD. A modeling analysis of the effects of molecular size and binding affinity on tumor targeting. Mol Cancer Ther. 2009;8(10):2861-2871.

34. Huang X, Peng X, Wang Y, et al. A reexamination of active and passive tumor targeting by using rod-shaped gold nanocrystals and covalently conjugated peptide ligands. ACS Nano. 2010;4(10):5887-5896.

35. Sobolev AS, Jans DA, Rosenkranz AA. Targeted intracellular delivery of photosensitizers. Prog Biophys Mol Biol. 2000;73(1):51-90.

36. Marotta DE, Cao W, Wileyto EP, et al. Evaluation of bacteriochlorophyllreconstituted low-density lipoprotein nanoparticles for photodynamic therapy efficacy in vivo. Nanomedicine (Lond). 2011;6(3):475-487.
37. Cunderlikova B, Kongshaug M, Gangeskar L, Moan J. Increased binding of chlorin $\mathrm{e}_{6}$ to lipoproteins at low $\mathrm{pH}$ values. Int J Biochem Cell Biol. 2000;32(7):759-768.

38. Mojzisova H, Bonneau S, Vever-Bizet C, Brault D. The pH-dependent distribution of the photosensitizer chlorin $\mathrm{e}_{6}$ among plasma proteins and membranes: a physico-chemical approach. Biochim Biophys Acta. 2007;1768(2):366-374.

39. Seki T, Fang J, Maeda H. Tumor-targeted macromolecular drug delivery based on the enhanced permeability and retention effect in solid tumor. In: Lu Y, Mahato RI, editors. Pharmaceutical Perspectives of Cancer Therapeutics. New York: Springer Science and Business Media, LLC; 2009.

40. Rajman I, Eacho PI, Chowienczyk PJ, Ritter JM. LDL Particle size: an important drug target? Br J Clin Pharmacol. 1999;48(2):125-133.

41. Leunig M, Richert C, Gamarra F, et al. Tumour localisation kinetics of photofrin and three synthetic porphyrinoids in an amelanotic melanoma of the hamster. Br J Cancer. 1993;68(2):225-234.

42. Conti E, Izaurralde E. Nuclearcytoplasmic transport enters the atomic age. Curr Opin Cell Biol. 2001;13(3):310-319.

43. Ribbeck K, Gorlich D. The permeability barrier of nuclear pore complexes appears to operate via hydrophobic exclusion. EMBO J. 2002;21(11):2664-2671.

44. Panté N, Kann M. Nuclear pore complex is able to transport macromolecules with diameters of about 39 nm. Mol Biol Cell. 2002;13(2): 425-434.

45. Chen P, Wang J, Hope K, et al. Nuclear localizing sequences promote nuclear translocation and enhance the radiotoxicity of the antiCD33 monoclonal antibody HUM195 labeled with ${ }^{111}$ In in human myeloid leukemia cells. J Nucl Med. 2006;47(5):827-836.

46. Costantini D, Chan C, Cai Z, Vallis KA, Reilly RM. ${ }^{111}$ In-labeled trastuzumab (Herceptin) modified with nuclear localization sequence (NLS): an auger electron-emitting radiotherapeutic agent for HER2/ Neu-amplified breast cancer. J Nucl Med. 2007;48(8):1357-1368.

47. Dolmans DE, Fukumura D, Jain RK. Photodynamic therapy for cancer. Nat Rev Cancer. 2003;3(5):380-387.

48. Chin WWL, Heng PWS, Thong PSP, Bhuvaneswari, et al. Improved formulation of photosensitizer chlorin $\mathrm{e}_{6}$ polyvinylpyrrolidone for fluorescence diagnostic imaging and photodynamic therapy of human cancer. Eur J Pharm Biopharm. 2008;69(3):1083-1093.

49. Brown SB, Brown EA, Walker I. The present and future role of photodynamic therapy in cancer treatment. Lancet Oncol. 2004;5(8): 497-508.

50. Rosenkranz AA, Vaidyanathan G, Pozzi OR, Lunin VG, Zalutsky MR, Sobolev AS. Engineered modular recombinant transporters: application of new platform for targeted radiotherapeutic agents to alpha-particle emitting 211 At. Int J Radiat Oncol Biol Phys. 2008;72(1):193-200.

51. Pautler M, Brenner S. Nanomedicine: promises and challenges for the future of public health. Int J Nanomedicine . 2010;5:803-809.

52. Adair JH, Parette MP, Altinoğlu EI, Kester M. Nanoparticulate alternatives for drug delivery. ACS Nano. 2010;4(9):4967-4970.

53. Vogel N, Jung M, Bocchio NL, Retsch M, Kreiter M, Koper I. Reusable localized surface plasmon sensors based on ultrastable nanostructures. Small. 2010;6(1):104-109.

54. Dalwadi G, Benson HA, Chen Y. Comparison of diafiltration and tangential flow filtration for purification of nanoparticle suspensions. Pharm Res. 2005;22(12):2152-2162. 


\section{Supplementary data} Evaluation of MNT functionality after freeze-drying

Stability and convenience are important factors in evaluating the potential utility of a nanosystem as a platform for the development of therapeutics. To address this issue, the functional properties of the modular nanotransporter (MNT) and the MNT-photosensitizer conjugates described in this study have been investigated after being subjected to freeze-drying. The MNT, comprising epidermal growth factor (EGF) for targeting the epidermal growth factor receptor (EGFR) that is overexpressed on several cancers, including head and neck, breast carcinoma, and glioblastoma, the optimized nuclear localization sequence from SV40 large tumor antigen (NLS), the Escherichia coli hemoglobin-like protein (HMP) as a carrier module, and a translocation domain of diphtheria toxin as the endosomolytic amphipathic module (DTox) (DTox-HMP-NLS-EGF) samples were snap-frozen in liquid nitrogen in phosphate-buffered saline $(150 \mathrm{mM} \mathrm{NaCl}$, $10 \mathrm{mM}$ sodium phosphate, $\mathrm{pH}$ 8) and freeze-dried. Thereafter, the preparations were reconstituted by the addition of deionized water. This procedure did not affect the solubility of the MNT and its affinity for EGF receptors on A431 cells (Figure S1A). Sixteen months of storage of freeze-dried DTox-HMP-NLS-EGF under different conditions did not significantly change its binding affinity for the EGF receptor on A431 cells (Figure S1B).

\section{In vivo ${ }^{125}$-labeled MNT tissue distribution}

As an initial investigation of the feasibility of utilizing MNT for targeted delivery of drugs such as photosensitizers or radionuclides emitting short range radiation to tumors in vivo, the whole body distribution of ${ }^{125}$ I-labeled MNT was determined in mice bearing subcutaneous B16-F1 melanoma tumors (Figure S3). However, our primary focus was on measuring tumor/skin and tumor/muscle ratios because of the potential utility of this $\alpha$-MSH receptor-targeted MNT for treatment of melanoma by photodynamic therapy.

It is worth noting that even though the level of $\alpha$-MSH receptors expressed on B16-F1 cells (about 10,000 receptors per cell $1^{4}$ ) is relatively low compared, for example,
A

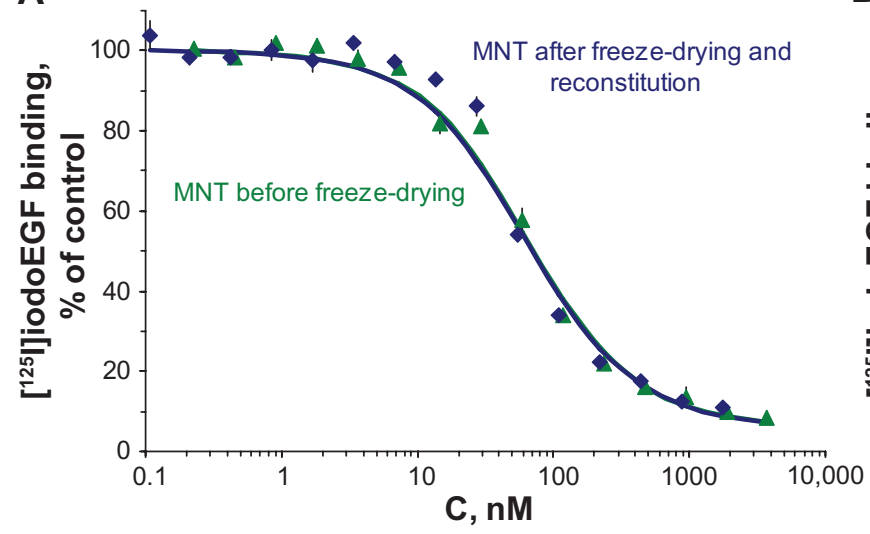

B

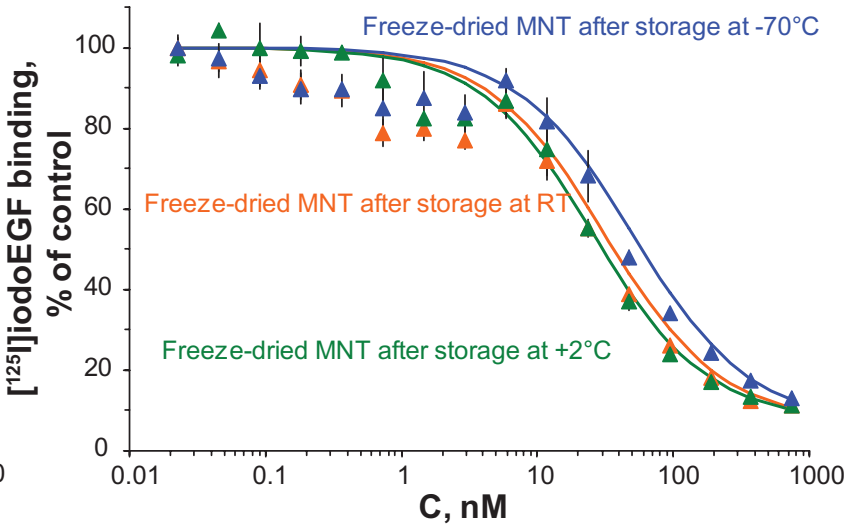

Figure SI Competition for binding to A43I cells with [ ${ }^{125}$ I] iodoEGF for DTox-HMP-NLS-EGF. (A) Influence of freeze-drying on binding DTox-HMP-NLS-EGF with A43I cells. Green triangles and line are freshly purified DTox-HMP-NLS-EGF (the association constant, $\left.\mathrm{K}_{\mathrm{a}}=(0.054 \pm 0.050) \times 10^{9} \mathrm{~L} / \mathrm{mol}\right)$, dark blue rhombi and fitted line are freeze-dried and reconstituted preparations $\left(\mathrm{K}_{\mathrm{a}}=(0.046 \pm 0.050) \times 10^{9} \mathrm{~L} / \mathrm{mol}\right)$. (B) Influence of different storage conditions for 16 months on binding of freeze-dried DTox-HMP-NLS-EGF to A43I cells. Green triangles and fitted line are DTox-HMP-NLS-EGF after the storage at $2^{\circ} \mathrm{C}\left(\mathrm{K}_{\mathrm{a}}=(0.074 \pm 0.0 \mathrm{II}) \times 10^{\circ} \mathrm{L} / \mathrm{mol}\right)$; orange triangles and fitted line are DTox-HMP-NLS-EGF after the storage at room temperature $\left(\mathrm{K}=(0.059 \pm 0.010) \times 10^{9} \mathrm{~L} / \mathrm{mol}\right)$; light blue triangles and fitted line are DTox-HMP-NLS$\mathrm{EGF}$ after the storage at $-70^{\circ} \mathrm{C}\left(\mathrm{K}_{\mathrm{a}}=(0.037 \pm 0.005) \times 10^{9} \mathrm{~L} / \mathrm{mol}\right)$. Human recombinant EGF was labeled with ${ }^{125}$ using lodogen to an initial specific activity of $4 \mathrm{IO} \mathrm{Ci} / \mathrm{mmol}$ and purified by gel filtration over a PD- 10 column (GE Healthcare). Competition experiments were carried out in 48-well plates with $2 \mathrm{nM}$ of [ $\left.{ }^{125} \mathrm{I}\right] \mathrm{iodoEGF}$ and incremental concentrations of MNT in $200 \mu \mathrm{L}$ of Dulbecco's Modified Eagle Medium supplemented with $20 \mathrm{mM} \mathrm{HEPES}$ and $20 \mathrm{mg} / \mathrm{mL}$ bovine serum albumin, pH 7.3. The plates were incubated at $4^{\circ} \mathrm{C}$ for 20 hours, washed three times with Hanks' solution containing bovine serum albumin, then cells were lysed with $0.5 \mathrm{M}$ NaOH, and the radioactivity in the cell lysates was measured with a gamma counter. The affinity constant of [125I]iodoEGF to EGF receptors $\left((0.149 \pm 0.015) \times 10^{9} \mathrm{~L} / \mathrm{mol}^{12}\right)$ was assessed after experiments with binding of incrementing concentrations of the labeled EGF using SigmaPlot 10 software. Nonspecific binding, measured by coincubation with I $\mu$ M non-labeled EGF, did not exceed $5 \%$ of total binding. The association constants for ligand binding were calculated by nonlinear regression of binding data' with a one-site binding model. All experiments were carried out in triplicate, and error bars represent the SEM. The phototoxicity of DTox-HMP-NLS-EGF-bacteriochlorin $p$ for A43I cells was not affected by freeze-drying/reconstitution (Figure S2). The $\mathrm{EC}_{50}$ determined for the MNT-photosensitizer conjugate before and after freeze drying/reconstitution were $3.4 \pm 0.5 \mathrm{nM}$ and $4.2 \pm 1.6 \mathrm{nM}$, respectively $(P>0.7)$. Incubation of A43I cells with MNT DTox-HMP-NLS-EGF without subsequent irradiation did not affect cell growth up to MNT concentrations sufficient for complete photodynamic mediated cell death. Free photosensitizer (chlorin $\mathrm{e}_{6}$ ) did not affect cell viability at the irradiation doses used for this particular experiment $\left(270 \mathrm{~kJ} / \mathrm{cm}^{2}\right)$, as well as up to more than $500 \mathrm{~kJ} / \mathrm{cm}^{2} .{ }^{3}$

Abbreviations: MNT, modular nanotransporter; DTox, translocation domain of diphtheria toxin; HMP, Escherichia coli hemoglobin-like protein; NLS, nuclear localization sequence; EGF, epidermal growth factor; SEM, standard error of the mean. 


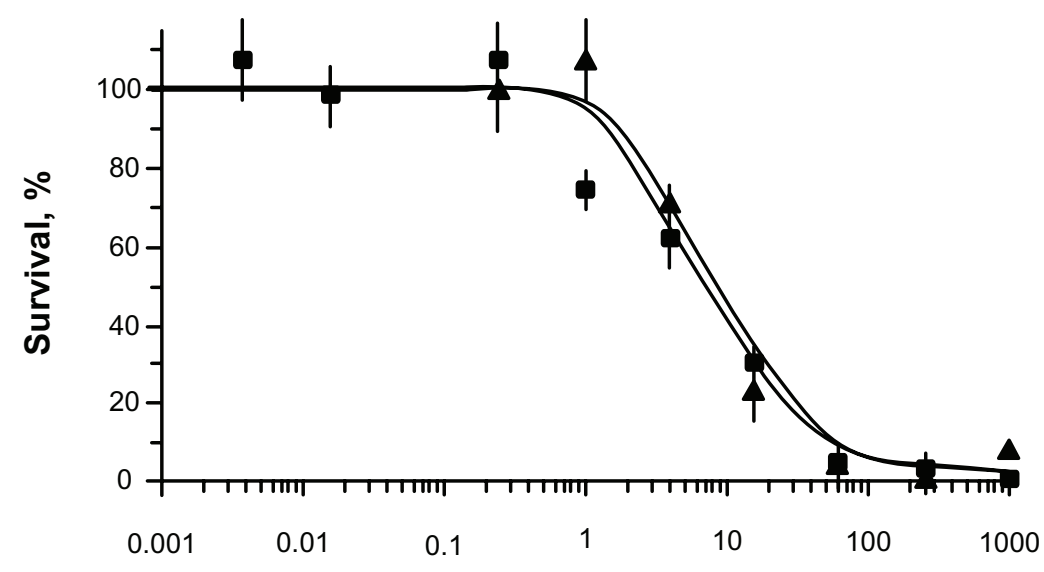

\section{Concentration, $\mathrm{nM}$}

Figure S2 Photocytotoxicity of DTox-HMP-NLS-EGF-bacteriochlorin $p$ before (squares) and after (triangles) freeze-drying and reconstitution. The A43I cells were seeded into 96-well plates at a density of 2000 cells per well. After 24 hours, the cells were incubated for 20 hours at $37^{\circ} \mathrm{C}$ with DTox-HMP-NLS-EGF-bacteriochlorin $p$ conjugate, washed three times with Hanks' solution, placed into Dulbecco's Modified Eagle Medium supplemented with $10 \%$ fetal calf serum for 3 hours, washed three times with Hanks' solution, and placed into Dulbecco's Modified Eagle Medium with $2 \mathrm{mg} / \mathrm{mL}$ bovine serum albumin. The cells were then illuminated with a slide projector at $270 \mathrm{~kJ} / \mathrm{m}^{2}$ and grown under $5 \% \mathrm{CO}_{2}$. Survival of cells in wells not exposed to MNT-photosensitizer was considered as $100 \%$ survival. Cell viability was determined after 3-4 days using methylene blue staining according to the method of Finlay et al. ${ }^{2} \mathrm{EC}_{50}$ values were calculated by nonlinear regression according to a four-parameter logistic equation (SigmaPlot 10). The experiments were carried out in six repeats, and error bars are the SEM.

Abbreviations: MNT, modular nanotransporter; DTox, translocation domain of diphtheria toxin; HMP, Escherichia coli hemoglobin-like protein; NLS, nuclear localization sequence; EGF, epidermal growth factor; SEM, standard error of the mean.

with the 340,000 sites/per cell reported for high molecular weight melanoma-associated antigen ${ }^{5}$ (HMW-MAA), the tumor-targeting properties of MNT were comparable with those for anti-HMW-MAA monoclonal antibody-based constructs. ${ }^{5,6}$ Moreover, due to the modular structure of MNT, which enables easy tailoring, it could be possible, for example, to reduce liver uptake by substituting the current (His) ${ }_{6}$-tag with an HEHEHE tag, which has recently

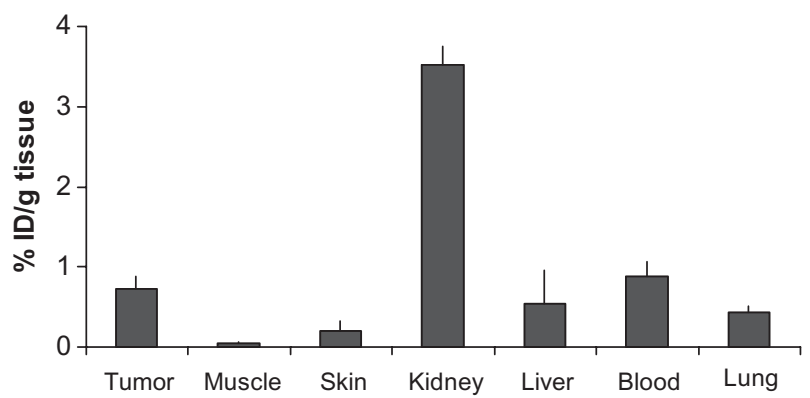

Figure S3 Biodistribution of ${ }^{125}$ activity in female BI6-FI melanoma-bearing C57 black/6] mice 3 hours after intravenous injection of $850 \mu \mathrm{g}$ of ${ }^{125}$ l-labeled DTox-HMPNLS- $\alpha M S H$. The concentration of radioactivity in different organs is expressed as \%ID/g and presented as an average value from three animals \pm SEM. Female C57 black/6 6 mice were inoculated subcutaneously with $1 \cdot 10^{6} \mathrm{BI} 6-\mathrm{FI}$ murine melanoma cells and 13 days later, $850 \mu \mathrm{g}$ (specific activity $6.5 \mu \mathrm{Ci} / \mathrm{mg}$ ) of ${ }^{125}$-labeled DTox-HMP-NLS- $\alpha M S H$ were injected intravenously in $500 \mu \mathrm{L}$ of saline with $50 \mu \mathrm{g} / \mathrm{mL}$ gentamicin. Three hours after injection, the mice were anesthetized, euthanized, and their tumors and other organs and tissues were removed, weighed, and counted for ${ }^{125}$ (RiaGamma I27I, LKB). The concentration of radioactivity was calculated as a ratio of ${ }^{125} \mathrm{I}$ counts per gram of tissue. Abbreviations: MNT, modular nanotransporter; DTox, translocation domain of diphtheria toxin; HMP, Escherichia coli hemoglobin-like protein; NLS, nuclear localization sequence; EGF, epidermal growth factor; SEM, standard error of the mean. been demonstrated to result in up to 19 -fold lower liver accumulation.?

\section{Materials and methods Delayed type hypersensitivity reaction}

Female C57 black/6J mice $(\mathrm{n}=11,20-25 \mathrm{~g})$ were injected subcutaneously with DTox-HMP-NLS- $\alpha$ MSH $(60 \mu \mathrm{L}$, $2 \mathrm{mg} / \mathrm{mL}$ Dulbecco's Modified Eagle Medium) mixed with Freund's complete adjuvant (1:1, v/v, Sigma). After 5 days, one hind foot pad of each mouse was injected with DToxHMP-NLS- $\alpha$ MSH (40 $\mu \mathrm{L}, 2 \mathrm{mg} / \mathrm{mL}$ ); the collateral foot was injected with only Dulbecco's Modified Eagle Medium (experimental group). A control group of mice $(n=8)$ were not injected with MNT/Freund's adjuvant. Edema was measured 24 hours later in foot pads of the experimental ( $m_{M N T \text { exp }}$, and collateral, $\left.m_{D M E M, \text { exp }}\right)$ and control $\left(m_{D M E M, c o n t r}\right)$ groups ${ }^{8}$ and expressed as:

$$
\begin{aligned}
\Delta D T H \%= & \left(\frac{m_{M N T, \exp }-m_{D M E M, \exp }}{m_{D M E M, \exp }}-\frac{m_{M N T, \exp }-m_{D M E M, \text { contr }}}{m_{D M E M, \text { contr }}}\right) \\
& \times 100 \%
\end{aligned}
$$

\section{Preparation of primary rabbit anti-MNT antibodies}

The antibodies against MNT were raised in rabbits, according to the method described by Burns. ${ }^{9}$ Briefly, 1-year old 


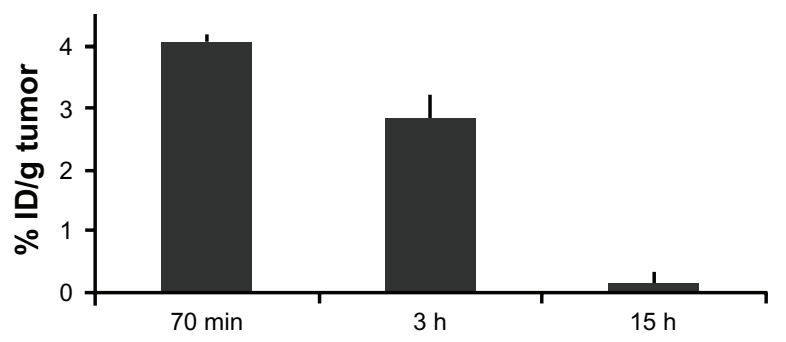

Time after iv injection of ${ }^{125 \mid-D T o x-H M P-N L S-\alpha M S H}$

Figure S4 Kinetics of tumor uptake of ${ }^{125} \mathrm{I}$ activity after intravenous injection of I I $\mu$ g $^{125}$ I-labeled DTox-HMP-NLS- $\alpha$ MSH in B I6-FI melanoma-bearing C57 black/6] mice. The concentration of radioactivity in tumor is expressed as $\% \mathrm{ID} / \mathrm{g}$ and presented as an average value from three animals \pm SEM.

Abbreviations: iv, intravenous; MNT, modular nanotransporter; DTox, translocation domain of diphtheria toxin; HMP, Escherichia coli hemoglobin-like protein; NLS, nuclear localization sequence; EGF, epidermal growth factor; SEM, standard error of the mean.

female rabbits (weight approximately $3.5 \mathrm{~kg}$ ) were firstly immunized subcutaneously with $0.7 \mathrm{~mL}$ at each site using a HMP-NLS- $\alpha M S H$ and complete Freund's adjuvant mixture (1:1, final concentration of HMP-NLS- $\alpha$ MSH $0.35 \mathrm{mg} / \mathrm{mL}$ ). The injections were performed into two rows of four sites equidistantly spaced along the rabbit's back and into both knee joint capsules. Rabbits were reimmunized three more times by subcutaneous injections of $0.5 \mathrm{~mL}$ each into four sites on the back at 7, 37, and 44 days. Donor bleeds were taken from an ear artery after the second and third immunizations. The antiserum was separated from the clotted blood by centrifugation and stored at $-20^{\circ} \mathrm{C}$.

The immunoglobulin fraction was obtained by ammonium persulfate precipitation. Briefly, cooled to $4^{\circ} \mathrm{C}$, ammonium persulfate solution $(800 \mathrm{~g} / \mathrm{L})$ was added to antiserum at a final concentration of $28 \%$. The resulting mixture was centrifuged at $4^{\circ} \mathrm{C}$ at $20,000 \mathrm{~g}$ for 20 minutes, and the supernatant was then precipitated again by ammonium persulfate (up to 50\%) and centrifuged as described above. The pellet was dissolved in phosphate-buffered saline. This procedure was repeated twice. The purified immunoglobulin fraction was then finally purified by affinity chromatography using the immobilized antigen on $\mathrm{CNBr}$ Sepharose. The affinity of the purified antibodies to the antigen was assayed by plate-trapped double-antibody sandwich enzyme-linked immunosorbent assay. ${ }^{10}$

\section{Tumor response}

Tumor growth was measured at regular intervals with microcalipers in two orthogonal dimensions; tumor volume was calculated according to formula $\mathrm{V}=0.5 \times$ length $\times$ width. Animals were euthanized when the tumor volume exceeded $1200 \mathrm{~mm}^{3}$, in the case of tumor ulceration, or other signs of animal distress. Survival was recorded as the percentage of animals surviving on a given day.

\section{References}

1. Zakharova OM, Rosenkranz AA, Sobolev AS. Modification of fluid lipid and mobile protein fractions of reticulocyte plasma membranes affects agonist-stimulated adenylate cyclase. Application of the percolation theory. Biochim Biophys Acta. 1995;1236(1):177-184.

2. Finlay GJ, Baguley BC, Wilson WR. A semiautomated microculture method for investigating growth inhibitory effects of cytotoxic compounds on exponentially growing carcinoma cells. Anal Biochem. 1984; 139(2):272-279.

3. Gilyazova DG, Rosenkranz AA, Gulak PV, et al. Recombinant modular transporters on the basis of epidermal growth factor for targeted intracellular delivery of photosensitizers. Proc SPIE. 2005;5973: 59730E1-E10.

4. Siegrist W, Solca F, Stutz S, et al. Characterization of receptors for $\alpha$-melanocyte-stimulating hormone on human melanoma cells. Cancer Res. 1989;49(22):6352-1658.

5. Le Doussal JM, Gruaz-Guyon A, Martin M, Gautherot E, Delaage M, Barbet J. Targeting of indium 111-labeled bivalent hapten to human melanoma mediated by bispecific monoclonal antibody conjugates: imaging of tumors hosted in nude mice. Cancer Res. 1990;50(11):3445-3452.

6. Kang N, Hamilton S, Odili J, Wilson G, Kupsch J. In vivo targeting of malignant melanoma by ${ }^{125}$ iodine- and ${ }^{99 m}$ technetium-labeled singlechain Fv fragments against high molecular weight melanoma-associated antigen. Clin Cancer Res. 2000;6(12):4921-4931.

7. Hofstrom C, Orlova A, Altai M, Wangsell F, Graslund T, Tolmachev V. Use of a HEHEHE purification tag instead of a hexahistidine tag improves biodistribution of affibody molecules site-specifically labeled with (99m)Tc, (111)In, and (125)I. J Med Chem . 2011;54(11):3817-3826.

8. Biondo C, Beninati C, Delfino D, et al. Identification and cloning of a cryptococcal deacetylase that produces protective immune responses. Infect Immun. 2002;70(5):2383-2391.

9. Burns R. Antibody production. In: Walker JM, editor. The Protein Protocols Handbook. Totowa, NJ: Humana Press; 2002.

10. Kemeny DM, Chandler S, editors. ELISA and Other Solid Phase Immunoassays: Theoretical and Practical Aspects. Chichester, NY: John Wiley \& Sons; 1988.
International Journal of Nanomedicine

\section{Publish your work in this journal}

The International Journal of Nanomedicine is an international, peerreviewed journal focusing on the application of nanotechnology in diagnostics, therapeutics, and drug delivery systems throughout the biomedical field. This journal is indexed on PubMed Central, MedLine, CAS, SciSearch ${ }^{\circledR}$, Current Contents ${ }^{\circledR} /$ Clinical Medicine,

\section{Dovepress}

Journal Citation Reports/Science Edition, EMBase, Scopus and the Elsevier Bibliographic databases. The manuscript management system is completely online and includes a very quick and fair peer-review system, which is all easy to use. Visit http://www.dovepress.com/ testimonials.php to read real quotes from published authors. 